
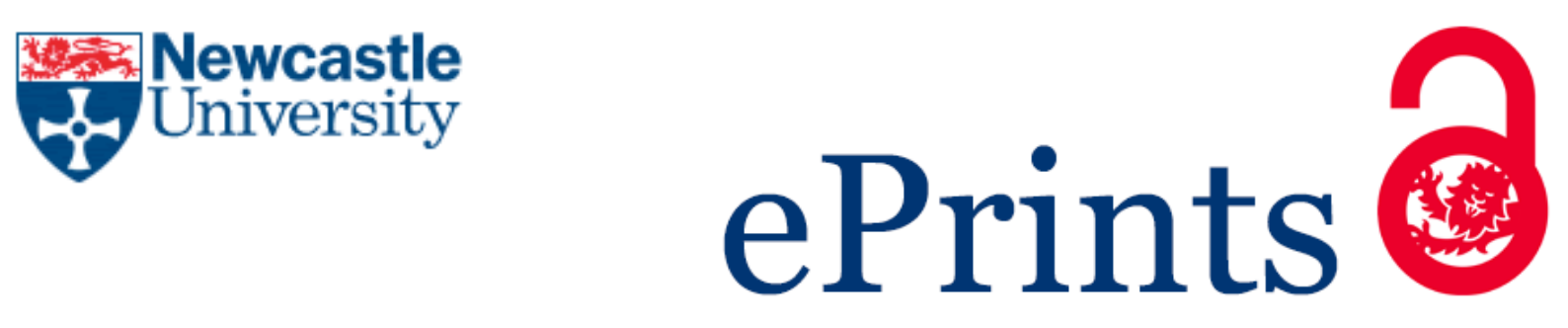

Galhenage TP, Hoffman D, Silbert SD, Stafslien SJ, Daniels J, Miljkovic T, Finlay JA, Franco SC, Clare AS, Nedved BT, Hadfield MG, Wendt DE, Waltz G, Brewer L, Teo SLM, Lim C-S, Webster DC.

Fouling-release performance of silicone oil-modified siloxane-polyurethane coatings.

ACS Applied Materials \& Interfaces (2016)

DOI: http://dx.doi.org/10.1021/acsami.6b09484

\title{
Copyright:
}

This document is the Accepted Manuscript version of a Published Work that appeared in final form in ACS Applied Materials \& Interfaces, copyright (C) American Chemical Society after peer review and technical editing by the publisher. To access the final edited and published work see

http://dx.doi.org/10.1021/acsami.6b09484

Date deposited:

$04 / 10 / 2016$

Embargo release date:

03 October 2017 


\section{Fouling-release performance of silicone oil-modified siloxane-polyurethane coatings}

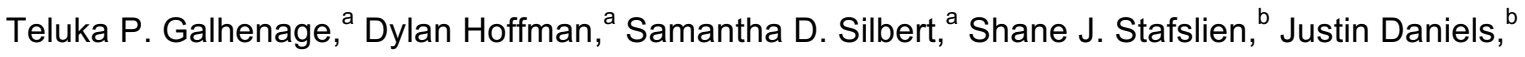
Tatjana Miljkovic, ${ }^{c}$ John A. Finlay, ${ }^{d}$ Sofia C. Franco, ${ }^{d}$ Anthony S. Clare,${ }^{d}$ Brian T. Nedved, ${ }^{e}$ Michael G. Hadfield, ${ }^{\mathrm{e}}$ Dean E. Wendt, ${ }^{\mathrm{f}}$ Grant Waltz, ${ }^{\mathrm{f}}$ Lenora Brewer, ${ }^{\mathrm{f}}$ Serena L.M. Teo, ${ }^{g}$ Lim Chin-Sing, ${ }^{9}$ Dean C. Webster $^{\mathrm{a}^{*}}$

${ }^{a}$ Department of Coatings and Polymeric Materials, North Dakota State University, Fargo ND 58108, USA

${ }^{\mathrm{b}}$ Center for Nanoscale Science and Engineering, North Dakota State University, Fargo, ND 58108, USA

${ }^{c}$ Department of Statistics, Miami University, Oxford, OH 45056, USA

${ }^{d}$ School of Marine Science and Technology, Newcastle University, Newcastle upon Tyne, NE1 7RU, UK

${ }^{\text {e } K e w a l o ~ M a r i n e ~ L a b o r a t o r y, ~ U n i v e r s i t y ~ o f ~ H a w a i i ~ a t ~ M a n o a, ~ H o n o l u l u ~ H I ~ 96813, ~ U S A ~}$

${ }^{\mathrm{f} C e n t e r ~ f o r ~ C o a s t a l ~ M a r i n e ~ S c i e n c e s, ~ B i o l o g i c a l ~ S c i e n c e s ~ D e p a r t m e n t, ~ C a l i f o r n i a ~ P o l y t e c h n i c ~ S t a t e ~}$ University, San Luis Obispo CA 93407, USA

${ }^{9}$ Tropical Marine Science Institute, National University of Singapore, Singapore 119227

*Corresponding Author: email: dean.webster@ndsu.edu; Phone: 701-231-8709

Keywords: siloxane-polyurethane coatings, phenylmethyl silicone oil, fouling release coatings, field immersion assessments 


\section{Abstract}

The effect of incorporation of silicone oils into a siloxane-polyurethane fouling-release coatings system was explored. Incorporation of phenylmethyl silicone oil has been shown to improve the fouling-release performance of silicone-based fouling-release coatings through increased interfacial slippage. The extent of improvement is highly dependent upon the type and composition of silicone oil used. The siloxanepolyurethane (SiPU) coating system is a tough fouling-release solution, which combines the mechanical durability of polyurethane while maintaining comparable fouling-release performance with regard to commercial standards. To further improve the fouling-release performance of the siloxane-PU coating system, the use of phenylmethyl silicones oils was studied. Coatings formulations were prepared incorporating phenylmethyl silicone oils having a range of compositions and viscosities. Contact angle and surface energy measurements were conducted to evaluate the surface wettability of the coatings. X-ray photoelectron spectroscopy (XPS) depth profiling experiments demonstrated self-stratification of silicone oil along with siloxane to the coating-air interface. Several coating formulations displayed improved or comparable fouling-release performance to commercial standards during laboratory biological assay tests for microalgae (Navicula incerta), macroalgae (Ulva linza), adult barnacles (Balanus amphitrite syn. Amphibalanus amphitrite) and mussels (Geukensia demissa). Selected silicone oil-modified siloxane-PU coatings also demonstrated comparable fouling-release performance in field immersion trials. In general, modifying the siloxane-PU fouling-release coatings with a small amount (1-5\% wt basis) of phenylmethyl silicone oil resulted in improved performance in several laboratory biological assays and in long-term field immersion assessments. 


\section{Introduction}

Marine biofouling is the unwanted growth and accumulation of biological organisms on materials submerged in seawater. ${ }^{1}$ The process of marine biofouling is a complex phenomenon that can involve more than 4000 marine organisms in multiple stages (Figure 1). ${ }^{1}$ Marine biofouling processes begin as soon as a structure is immersed in seawater. First a conditioning film is formed due to the adsorption of organic molecules present in the marine environment. The fouling process is highly dynamic and marine bacteria colonize the surface quickly $(\mathrm{min})$ forming a bacterial biofilm. ${ }^{2}$ Slime forming algae (diatoms) also colonize the surface and contribute to the microfouling community. Macro-foulers such as barnacles and mussels tend to settle within a few days of immersion. However, fouling organisms may settle even without colonization or the presence of other marine organisms. ${ }^{2-3}$

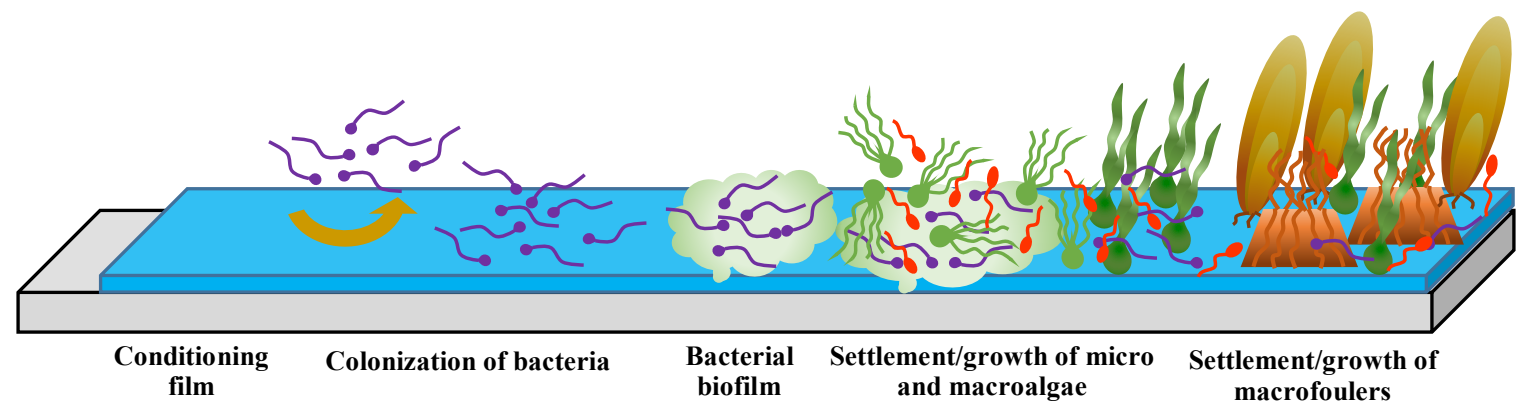

Figure 1: Fouling development on a structure submerged in seawater

Marine biofouling has caused significant economic and environmental penalties to the marine industry for centuries. ${ }^{4}$ It has been estimated that biofouling costs $\$ 1$ billion per year to the United States Navy alone. ${ }^{5}$ Continuous accumulation of microfouling and macrofouling biomass on ships' hulls creates frictional drag, which in turn contributes to reduction in ship speed and maneuverability. Estimates have shown that even a marginal $(2 \%)$ reduction in ship speed can reduce fuel efficiency significantly, especially for larger vessels. ${ }^{4}$ Fouling of ships' hulls can also lead to increased frequency of dry docking, causing severe economic penalties to ship owners. On the other hand, given the extensive and global nature of shipping routes, biofouling also poses an environmental threat through the introduction of non-native species. ${ }^{6}$

Historically, ships' hulls made from copper alloys and lead sheaths were used to contend with biofouling. ${ }^{4}$,

${ }^{7}$ Even though they were very effective antifouling strategies, issues with corrosion of iron hulls and declining 
availability of resources limited their use in the post medieval era. Thus, antifouling paints with active biocides were investigated as a possible solution in the 1900 s. $^{7}$ Biofouling was managed well with the introduction of tributyl tin (TBT) based self-polishing copolymer coatings in the 1970s until their toxicity to non-targeted marine organisms was discovered several decades later resulting in restrictions of their use in France. ${ }^{3,8}$ In 2003, the use of TBT in antifouling coatings was largely banned by an International Maritime Organization (IMO) treaty due to the harmful effects of TBT to aquatic ecosystems. ${ }^{3}$

Today antifouling coatings using copper oxide and other organic biocides contribute to the majority of ship hull paints used. These antifouling coatings with active biocides function by the release of toxic substances, which are able to kill or deter settlement of organisms that come in contact with or near the surface. These coatings allow ships to maintain clean hulls for as long as 5-10 years. ${ }^{3}$ Fouling-release coatings were introduced in 1961 as a non-toxic alternative to biocide-based antifouling coatings, although they became a more widely mentioned topic between 1990 to $2000{ }^{1,3}$ Fouling-release coatings have no harmful chemical interactions and do not necessarily inhibit fouling, rather they provide a surface with significantly reduced adhesion strength to organisms. ${ }^{1,3,4}$ Ideally, fouling-release surfaces achieve 'self-cleaning' due to the hydrodynamic forces of the vessel moving through the water.

Although antifouling coatings with biocides are largely used to contend with biofouling, fouling-release coatings have remained of special interest due to the ever-increasing desire to eliminate the use of biocidecontaining paints. Polydimethyl siloxane (PDMS) elastomers are a commonly used system in most foulingrelease coatings and contribute to fouling-release properties due to their low surface energy and high elasticity. ${ }^{1,7}$ However, PDMS has poor mechanical durability and low adhesion to substrates and primers making it difficult to use in marine coatings. ${ }^{9,} 10$ Siloxane-polyurethane (SiPU) coatings invented in the Webster research group, on the other hand, have combined the mechanical and adhesion properties of polyurethanes and the fouling-release performance of siloxane. ${ }^{11,}{ }^{12}$ Siloxane-polyurethane coatings are a viable approach to combat biofouling with comparable performance to commercial fouling-release coatings. $^{13,14}$

Non-reactive silicone oils are known to be used in PDMS-based fouling-release coatings. ${ }^{15}$ The earliest reports of silicone oil additives in marine topcoats originated in $1977 .{ }^{16,17}$ Several studies suggest that the 
oil provides lubricity to the coating surface resulting in weaker adhesion of marine organisms. ${ }^{18-20}$ Therefore polydimethylsiloxane (PDMS) based elastomers can benefit from silicone oil to obtain improved fouling release properties. Truby et al. reported a decrease in barnacle and oyster adhesion strength to PDMS coatings with the addition of small amounts of phenylmethyl silicone oil during immersion studies conducted in Hawaii. ${ }^{15}$ However the observed differences in release properties are closely related to the chemical composition of the silicone oil and the degree of compatibility with the PDMS matrix. ${ }^{21,22}$ The amount of silicone oil used in coatings was varied from $1-10 \%$ based on the total solids of the formulation. Truby et al. also highlighted possible issues with the release of silicone oil into marine environments. The amount of silicone oil released by such coatings was, however, negligible and there is no direct threat to marine life given the extremely low toxicity of silicone. ${ }^{15}$

In this study, silicone oils with a range of phenylmethyl compositions were incorporated into a SiPU coating system at 1,2 and $5 \mathrm{wt} \%$ based on PDMS with the intention of obtaining improved fouling-release performance relative to the $1^{\text {st }}$ generation SiPU (A4-20) system without oil. ${ }^{14}$ Fouling-release performance of these silicone oil-modified coatings was also compared against the commercial fouling-release systems Intersleek $® 700$ and Intersleek $® 900$. Surface characterization of the experimental coatings was conducted using XPS, contact angle and surface energy measurements. Fouling-release performance of these coatings was evaluated using laboratory biological assays and field immersion studies at multiple test sites.

\section{Experimental}

\section{Materials}

Phenylmethyl silicone oils (PMM-1025, PMM-1043, PMM-5021, PMM-6025, PMM-0021, and PMM-0025) were purchased from Gelest Inc. Polyisocyanate Desmodur Z 4470 BA was provided by Bayer MaterialScience (now Covestro LLC). Acetylacetone, toluene, methyl amyl ketone (MAK) and dibutyltin diacetate (DBTDAc) were purchased from Sigma Aldrich. All reagents were used as received. An acrylic polyol containing $80 \%$ butyl acrylate (BA) and 20\% 2-hydroxyethyl acrylate (HEA) was selected for this study and synthesized as previously reported. ${ }^{23}$ An aminopropyl terminated poly(dimethylsiloxane) (APTPDMS) of $20,000 \mathrm{~g} / \mathrm{mol}$ molecular weight was synthesized as reported previously. ${ }^{14}$ Details of the synthesis of the acrylic polyol and siloxane are provided in the Supporting Information. 


\section{Experimental Design}

The study was designed using 6 types of phenylmethyl silicone oils at three levels of oil $(1 \%, 2 \%$ and $5 \%$ based on PDMS weight). Characteristics of the 6 silicone oils provided by the manufacturer are summarized in Table 1. The oils have phenylmethyl composition varying from $8 \%$ to $100 \%$, with $100 \%$ being the homopolymer of phenylmethyl silicone oil. The representative chemical structures of the phenylmethyl silicone oils used are shown in Figure 2. The oils were selected to have a range of viscosities based on their molecular weight to later understand correlations with fouling release performances. The coatings were designed as a two-factor factorial study where type of oil and weight percent of oil were considered as factors. Factor 1 (type of oil) had 6 levels and factor 2 (wt \% of oil) had 3 levels resulting in 18 different treatment combinations (Table 2).

a)

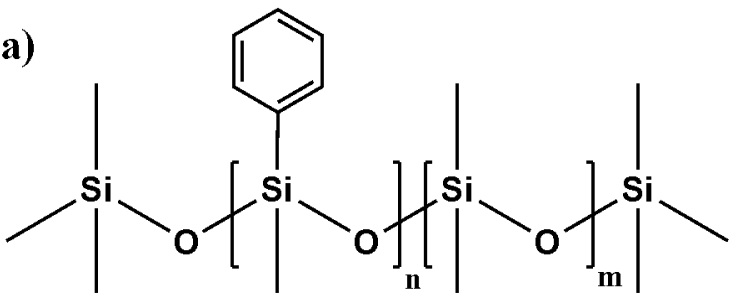

b)

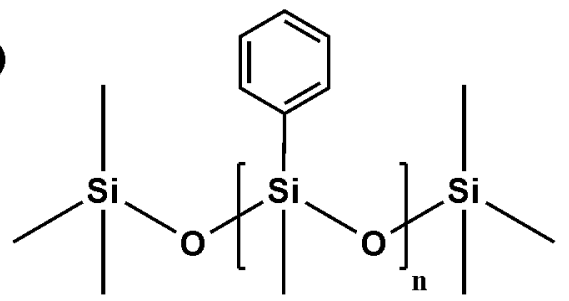

Figure 2: Chemical structure of silicone oils used for the experiment. a) phenylmethyl dimethyl siloxane copolymer oil and b) phenylmethyl siloxane homopolymer oil.

Table 1: Properties of the phenylmethyl silicone oils used in the study

\begin{tabular}{cccccc}
\hline Name of Oil & Type & $\begin{array}{c}\% \\
\text { Phenylmethyl }\end{array}$ & $\begin{array}{c}\text { Viscosity } \\
(\mathbf{c s})\end{array}$ & $\begin{array}{c}\text { Mw (g/mol) } \\
\text { Reported }\end{array}$ & $\begin{array}{c}\text { Surface } \\
\text { Tension } \\
(\mathbf{m N} / \mathbf{m})\end{array}$ \\
\hline PMM-1025 & Copolymer Oil & $8-12$ & 500 & $9000-11000$ & 24.4 \\
\hline PMM-1043 & Copolymer Oil & $8-12$ & 30000 & $40000-50000$ & 24.8 \\
\hline PMM-5021 & Copolymer Oil & $45-50$ & 125 & $2000-2200$ & 24.5 \\
\hline PMM-6025 & Copolymer Oil & $58-60$ & 500 & $3500-4000$ & - \\
\hline PMM-0021 & Homopolymer Oil & 100 & $100-200$ & $700-1200$ & - \\
\hline PMM-0025 & Homopolymer Oil & 100 & 500 & $2500-2700$ & 28.5 \\
\hline
\end{tabular}

\section{Coating Formulation}

A general formulation procedure described here was followed. The non-reactive components such as APTPDMS ( $20 \%$ by wt. based on the total solids of the formulation), corresponding silicone oil (1, 2 and $5 \%$ 
based on PDMS wt.), acrylic polyol, and pot life extender were combined in a glass vial and allowed to mix overnight. The next day, 1.1 equivalents (for 1 equivalent of hydroxyl and amine combined) of isocyanate (Desmodur Z4470 BA) and $0.05 \%$ of DBDTAc catalyst were added (using a diluted solution of $1 \%$ by wt in MAK). The formulations were allowed to mix for about an hour before coating preparation. Table 2 shows all the experimental coating formulations.

Table 2: Silicone oil-modified experimental coating compositions

\begin{tabular}{|c|c|c|c|}
\hline & \multicolumn{3}{|c|}{ Amount oil based on solids of } \\
& \multicolumn{3}{|c|}{ PDMS } \\
\hline Silicone Oil & $1 \%$ & $2 \%$ & $5 \%$ \\
\hline PMM 1025 & 1 & 7 & 13 \\
\hline PMM 1043 & 2 & 8 & 14 \\
\hline PMM 5021 & 3 & 9 & 15 \\
\hline PMM 6025 & 4 & 10 & 16 \\
\hline PMM 0021 & 5 & 11 & 17 \\
\hline PMM 0025 & 6 & 12 & 18 \\
\hline
\end{tabular}

\section{Coating Application and Curing}

Drawdowns were made using a wire wound drawdown bar to achieve $80 \mu \mathrm{m}$ dry film thickness on 8"x 4" aluminum panels previously primed with Intergard 264 marine grade primer. The coatings were allowed to cure for $24 \mathrm{~h}$ under ambient conditions inside a dust free cabinet, followed by forced curing in the oven at $80{ }^{\circ} \mathrm{C}$ for $45 \mathrm{~min}$. These panels were used for barnacle and mussel reattachment (1 panel per each test). Coatings for other biological assays (described later) were prepared by depositing $250 \mu \mathrm{L}$ of formulation in to 24-well plates modified with primed aluminum discs. ${ }^{24}$ These were also cured following the same procedure described above.

\section{Control and Standard Coatings}

As an internal control, the $1^{\text {st }}$ generation SiPU formulation (A4-20) was prepared. This is the base coating formulation without the added silicone oil. A pure polyurethane formulation without APT-PDMS was also prepared to be included as a control. Commercial coating standards, Dow Corning T2 (silicone elastomer), Intersleek $₫ 700$ and Intersleek $® 900$ (AkzoNobel International Paint), were prepared according to manufacturer's specifications to serve as standards. All internal control coatings and commercial standards 
were prepared on both primed aluminum panels and in 24-well plates in order to be characterized in parallel with the experimental coatings.

\section{Water Aging}

All the coatings prepared on both panels and plates were pre-leached in running tap water for 28 days (45 days of pre-leaching in the case of samples for green algae Ulva linza) in tanks separated by the oil type. The water tanks were equipped to automatically fill and empty every $4 \mathrm{~h}$. Water aging of the coatings is carried out for two purposes: To leach out any impurities that could interfere with the fouling-release assays and to determine if there are any significant surface rearrangements of the coatings after being on contact with water. ${ }^{25}$ All biological laboratory assays were carried out after the pre-leaching process was complete.

\section{Surface Characterization of Coatings}

All experimental coatings were characterized for water and methylene iodide contact angles (WCA and MICA) using a Symyx ${ }^{\circledR} /$ First Ten Angstroms ${ }^{\mathrm{TM}}$ surface energy system. Three measurements the contact angle of each test liquid were obtained using a CCD camera and First Ten Angstroms ${ }^{\mathrm{TM}}$ software. Then the average WCA and MICA contact angles were used to calculate the SE for each coating by Owens-Wendt method. ${ }^{26}$ Contact angle and SE analysis were performed both before and after water aging.

X-ray photoelectron spectroscopy (XPS) was utilized to investigate the effects of silicone oil incorporation

on coating morphology. A Thermo Scientific ${ }^{T M}$ K-Alpha ${ }^{T M}$ XPS equipped with monochromatic Al $K_{\alpha}(1486.68$ eV) X-ray source and $\mathrm{Ar}^{+}$ion source (up to $4000 \mathrm{eV}$ ) for depth profiling was used for the XPS experiments. Initially an etch rate calibration experiment was performed to determine the appropriate etch rate for depth profiling experiment using thin film of silicone elastomer of known thickness ( $287.3 \mathrm{~nm})$. Dow Corning T2 silicone elastomer was spin coated on a silicon wafer at a speed of $6000 \mathrm{rpm}$ for $35 \mathrm{~s}$ using a Laurell WS400A-6NPP spin coater. Following spin coating, the sample was carefully transferred to a dust free cabinet and allowed to cure under ambient conditions. For accurate film thickness measurements, a First Optec Micro Master Excimer laser was used to ablate and remove a thin strip of coating from the spin coated sample and then a KLA-Tencor profilometer was used to measure step height from the top of the coating to the wafer substrate. The thickness of the silicone elastomer was determined to be $287.3 \pm 25.3 \mathrm{~nm}$. Depth 
profiling of the silicone elastomer was performed using a $1000 \mathrm{eV} \mathrm{Ar}^{+}$source sputtering on a spot of $1 \mathrm{~mm}^{2}$ in $30 \mathrm{~s}$ intervals for about $50 \mathrm{~min}$ (until complete penetration into the silicon wafer). Chamber pressure was maintained below $1.5 \times 10^{-7}$ Torr. Photoemission lines for $\mathrm{C} 1 \mathrm{~s}, \mathrm{~N} 1 \mathrm{~s}, \mathrm{O} 1 \mathrm{~s}$, and Si $2 \mathrm{p}$ were collected after each etch for an interval of $5 \mathrm{~s}$ at constant analyzer pass energy $155 \mathrm{eV}$, and an energy increment of 0.167 $\mathrm{eV}$. Silicone elastomer etch rate with $\mathrm{Ar}^{+}$ion etch power of $1000 \mathrm{eV}$ was determined to be $0.0384 \mathrm{~nm} \mathrm{~s}^{-1}$.

Several experimental coatings prepared on aluminum substrates were analyzed through depth profiling using similar settings mentioned above. $\mathrm{Ar}^{+}$sputtering was performed on a spot of $1 \mathrm{~mm}^{2}$ of experimental coating with an etch power of $1000 \mathrm{eV}$ in 10 s intervals for $25-50$ min. Following each etch photoemission lines for $\mathrm{C} 1 \mathrm{~s}, \mathrm{~N}$ 1s, $\mathrm{O}$ 1s, and Si $2 \mathrm{p}$ were collected as described before. Atomic concentrations were determined using the integrated areas after subtracting the background and atomic sensitivity factors of $1.000,1.676,2.881$, and 0.900 for $\mathrm{C} 1 \mathrm{~s}, \mathrm{~N} 1 \mathrm{~s}, \mathrm{O} 1 \mathrm{~s}$, and Si $2 \mathrm{p}$ lines respectively. Previously determined etch rate was used to convert etch time to etch depth and atomic concentration with etch depth for each sample were plotted to observe composition variations.

\section{Laboratory Biological Assays}

\section{Growth and Release of the Macroalga (Ulva linza)}

A detailed description of the Ulva linza growth and removal assay using high-throughput screening methodologies can be found elsewhere. ${ }^{27}$ A brief description of the procedure is provided here. All 24-well plates for the $U$. linza removal assay were aged in water for 45 days. The coatings were equilibrated with filtered artificial seawater (ASW; Tropic Marin) for 2 hours $\mathrm{h}$ before starting the experiment. Then $1 \mathrm{~mL}$ of U. linza spores in a single strength enriched ASW suspension (with $3.3 \times 10^{5}$ spores $/ \mathrm{mL}$, adjusted to 0.05 OD at absorbance $660 \mathrm{~nm}$ ) was deposited into each coating well. Spores were allowed to settle and cultured for 6 days by incubating at $18{ }^{\circ} \mathrm{C}$ with a $16: 8$ light: dark cycle (photon flux density $15.39 \mathrm{Wm}^{-2}$ ) with nutrients renewed every $48 \mathrm{~h}$. To evaluate ease of removal the ASW medium was removed and three of the rows of wells were subjected to water-jetting at 9 and $67 \mathrm{kPa}$ using a spinning water-jet apparatus. One row of wells

was not subjected to the water jet and was used as the measure of growth. ${ }^{28}$ Biomass of sporelings in coated wells was determined using chlorophyll extraction. Chlorophyll was extracted by adding $1 \mathrm{~mL}$ of DMSO to each well and the fluorescence determined at excitation $360 \mathrm{~nm}$ and emission at $670 \mathrm{~nm}$ 
wavelengths. Fluorescence is directly proportional to the biomass present on each coating surface. The fluorescence from water-jetted vs. non-jetted wells was used to determine relative percent removal of sporelings.

\section{Growth and Release of Microalgae (Navicula incerta)}

The microalga (Navicula incerta) assay was conducted using methods described elsewhere. ${ }^{29,}{ }^{30}$ Briefly, coatings prepared in 24-well plates were used for assessments of diatom attachment and adhesion following 28 days of water immersion pre-conditioning in running tap water. A suspension with $4 \times 10^{5}$ cells $/ \mathrm{mL}$ of $N$. incerta (adjusted to $0.03 \mathrm{OD}$ at absorbance $660 \mathrm{~nm}$ ) in Guillard's F/2 medium was deposited into each well ( $1 \mathrm{~mL}$ per well) and cell attachment was encouraged by static incubation for $2 \mathrm{~h}$ under ambient conditions in the dark. Coating surfaces were then subjected to water-jet treatments. ${ }^{28}$ Three replicate wells did not receive the water-jet treatment so that initial cell attachment could be determined and three replicate wells were water-jetted at $138 \mathrm{kPa}(20 \mathrm{psi})$ for $10 \mathrm{~s}$. Microalgae biomass was quantified by extracting chlorophyll using $0.5 \mathrm{~mL}$ of DMSO and measuring fluorescence of the transferred extracts at an excitation wavelength of $360 \mathrm{~nm}$ and emission wavelength at $670 \mathrm{~nm}$. Relative fluorescence (RFU) measured from the extracts was considered directly proportional to the biomass present or remaining on the coating surfaces after water-jetting. Percent removal of attached microalgae was determined using relative fluorescence of non-jetted and water-jetted wells.

\section{Bacterial (Cellulophaga lytica) Biofilm Adhesion}

A detailed description of the marine bacterial retention and adhesion assays for evaluating fouling-release coatings can be found elsewhere. ${ }^{28,30-31}$ Similar to the microalgal attachment and adhesion assay, 24-well plates were incubated statically at $28^{\circ} \mathrm{C}$ for $24 \mathrm{~h}$ with a $1 \mathrm{~mL} /$ well of suspension consisting of the marine bacterium Cellulophaga lytica at $10^{7}$ cells $/ \mathrm{mL}$ concentration in ASW containing $0.5 \mathrm{~g} / \mathrm{L}$ peptone and $0.1 \mathrm{~g} / \mathrm{L}$ yeast extract. The ASW growth medium was then removed and the coatings were subjected to water-jet treatments. The first column of each coating ( 3 replicate wells) was not treated and served as the initial amount of bacterial biofilm growth. The second column (3 replicate wells) was subjected to water-jetting at $69 \mathrm{kPa}(10 \mathrm{psi})$ for $5 \mathrm{~s}$. Following water-jet treatments, the coating surfaces were stained with $0.5 \mathrm{~mL}$ of a crystal violet solution ( 0.3 wt. \% in deionized water) for 15 minutes and then rinsed three times with 
deionized water. After 1 hour of drying at ambient laboratory conditions, the crystal violet dye was extracted from the coating surfaces by adding $0.5 \mathrm{~mL}$ of $33 \%$ acetic acid solution for $15 \mathrm{~min}$. The resulting eluates were transferred to a 96 -well plate $(0.15 \mathrm{~mL} /$ coating replicate $)$ and subjected to absorbance measurements at $600 \mathrm{~nm}$ wavelength using a multi-well plate spectrophotometer. The absorbance values were considered to be directly proportional to the amount of bacterial biofilm present on coating surfaces before and after water-jetting treatments. Percent removal of bacterial biofilm was quantified by comparing the mean absorbance values of the non-jetted and water-jetted coating surfaces. ${ }^{27}$

\section{Adult Barnacle (Amphibalanus amphitrite) Adhesion}

An adult barnacle reattachment and adhesion assay was used to evaluate the fouling-release properties of the coatings towards macrofouling organisms. ${ }^{32,33}$ Barnacles were removed from silicone substrates sent from Duke University and placed on experimental coatings (5 barnacles per coating) using a customdesigned immobilization template. The immobilized barnacles were allowed to reattach and grow for 2 weeks via immersion in an ASW aquarium tank system with daily feedings of brine shrimp Artemia nauplii (Florida Aqua Farms). The number of non-attached barnacles was recorded and the attached barnacles were pushed off (in shear) using a hand-held force gauge mounted onto a semi-automated stage. Once the barnacles were dislodged, their basal plate areas were determined from scanned images using Sigma Scan Pro 5.0 software program. Barnacle adhesion strength (MPa) was calculated by dividing the peak force of removal by the basal plate area for each reattached barnacle. The average barnacle adhesion strength for each coating was reported as a function of the number of barnacles released with a measureable force and that exhibited no visible damage to the basis or shell plates.

\section{Mussel (Geukensia demissa) Adhesion}

The assessment of marine mussel adhesion to the coating surfaces was evaluated using a modified version of previously published protocols. ${ }^{34-36}$ Marine ribbed mussels (Geukensia demissa; 3-5 cm length) were received from Duke University Marine Laboratory in Beaufort, North Carolina, USA. Prior to the attachment study, a $4 \mathrm{~cm}$ long acetal plastic rod (product\# 98873A105, McMaster-Carr) was attached to each mussel perpendicular to the ventral edge, using a $3 \mathrm{M} \circledast$ acrylic adhesive (product\# 7467A135, McMaster-Carr). Six mussels were then immobilized on to each coating surface using a custom-designed template fabricated 
from PVC sheets. The coatings containing immobilized mussels were then placed in an ASW aquarium system and fed daily with live marine phytoplankton (DTs Premium Reef Blend Phytoplankton). The coatings were removed from the ASW aquarium tank system after three days of immersion and the total number of mussels exhibiting attachment of byssus threads was recorded for each coating. The plastic rod of each attached mussel was then affixed to individual 5 Newton load cells of a custom-built tensile force gauge where all mussels were pulled off simultaneously $\left(1 \mathrm{~mm} \mathrm{~s}{ }^{-1}\right.$ pull rate). The total force (Newtons) required to completely detach all byssus threads for each mussel was recorded and the mean value of the total number of attached mussels for each coating was calculated.

\section{Field Immersion Study}

Select experimental coatings were sent to static ocean immersion field testing sites in Hawaii, California, and Singapore to evaluate their fouling-release performance. Coating formulations 5 and 6 along with controls, A4-20 and Intersleek ${ }^{\circledR 900}$ were included in the field study. At each test site, panels were immersed in the ocean about $1 \mathrm{~m}$ deep from the water line. Every month, visual inspections were performed before and after water-jet treatments $(1.65$ or $0.69 \mathrm{MPa})$.

\section{Statistical Analysis}

The analysis of variance for completely randomized design and a cell-means model were performed in SAS 9.4. The GLM Procedure with Least Squares Means (LS-Means) was used to compute the LS-Means of each treatment combination of coating and oil type for a given percent removal in case of $U$. linza, microalgae and bacteria. Similarly, the LS-Means of each treatment combination of coating and oil type was computed for adhesion strength of adult barnacles. Five replicates were considered in each treatment combination of coating and oil type. Barnacle release scores were assigned based on zero MPa strength corresponding to score 100 and $0.4 \mathrm{MPa}$ strength corresponding to score zero following the equation

$$
100-\left(\left(\frac{F_{r}}{F_{0}}\right) \times 100\right)
$$

where $F_{r}$ is the adhesion strength of individual barnacle and $F_{0}$ is the maximum adhesion strength observed during the test. 
Adhesion strength of non-attached barnacles was considered to be zero. This allows for non-attached or broken barnacles for which adhesion strength was not recorded to be included in the statistical analysis. Significant difference for pairwise comparisons between treatments and five controls was defined at $p<$ 0.05 based on Tukey's test.

\section{Results and Discussion}

Biofouling can be a nuisance to marine organisms and plants which share the marine environment. Often, these marine organisms and plants have naturally evolved defensive anti-fouling and fouling-release strategies that are chemical, physical, mechanical or behavioral. ${ }^{37}$ Release of oils and mucus to weaken the adhesion of fouling organisms is a commonly observed physical strategy in nature. ${ }^{38}$ The oils provide slipperiness to the surface when needed allowing for the easy release of fouling. From early times scientists have attempted to employ this strategy in marine coatings for minimizing biofouling, although in 1970 s it

was investigated for fouling-release paint applications. ${ }^{16-17,39}$ Most commonly, a non-reactive silicone oil is incorporated into silicone elastomer paint formulations and the oil trapped in the matrix slowly exudes over time providing a similar effect as seen for some organisms. However, achieving continuous lubrication over a long period of time is quite challenging with a coating system.

Through this study, the question regarding whether a similar strategy would help to improve the foulingrelease performance of highly crosslinked SiPU marine coatings was addressed. Phenylmethyl silicone oil was chosen for the study given its surface tension being close to PDMS yet slightly higher, a strategy to have some control over the oil exuding behavior. In this study, a total of 18 experimental formulations modified with phenylmethyl silicone oil (Table 2) were evaluated for fouling-release performance along with several internal control coatings and commercial standards.

Water and methylene iodide contact angles were measured for the as-made coatings as well as following 28 days of water immersion. Figure 3 a. shows the contact angles of the coatings plotted against the coating compositions. The experimental coating surfaces showed water contact angles (WCA) in the range of $90^{\circ}$ $105^{\circ}$ suggesting hydrophobic character. Water contact angles for the silicone oil-modified SiPU coatings remained mostly unchanged after 28 days of water immersion. The WCA for A4-20 (siloxane-PU without 
silicone oil) was $\sim 102^{\circ}$, which is in the same range as silicone oil-modified siloxane-PU coatings signifying self-stratification of siloxane.

Methylene iodide contact angles (MICA) for silicone oil-modified coatings were in the range of $67-71^{\circ}$ before water immersion. Although experimental coatings 1-14 did not show much change in MICA after water aging, coatings $15-18$ showed an increase in MICA $\left(75-85^{\circ}\right)$ following water aging. Interestingly, the coatings which displayed increased WCA and MICA after water immersion were attributed to formulations modified with phenylmethyl content greater than $50 \%$ and oil amount $5 \%$. Figure 3 a. shows the trends in surface energy (SE) changes before and after water immersion. SE values for phenylmethyl silicone oilmodified coatings were very similar to each other prior to water aging. However, after water aging, a slight decrease in SE was observed for silicone oil-modified coatings 3-6, and 11-13. Coatings 2, 9, and 15-18 showed a significant decrease in SE mainly attributed to the increase in MICA highlighted before. Internal control A4-20 also demonstrated lower surface energy after water immersion. However, in general all coatings surfaces remained hydrophobic after water aging suggesting that no significant surface rearrangement had occurred. 

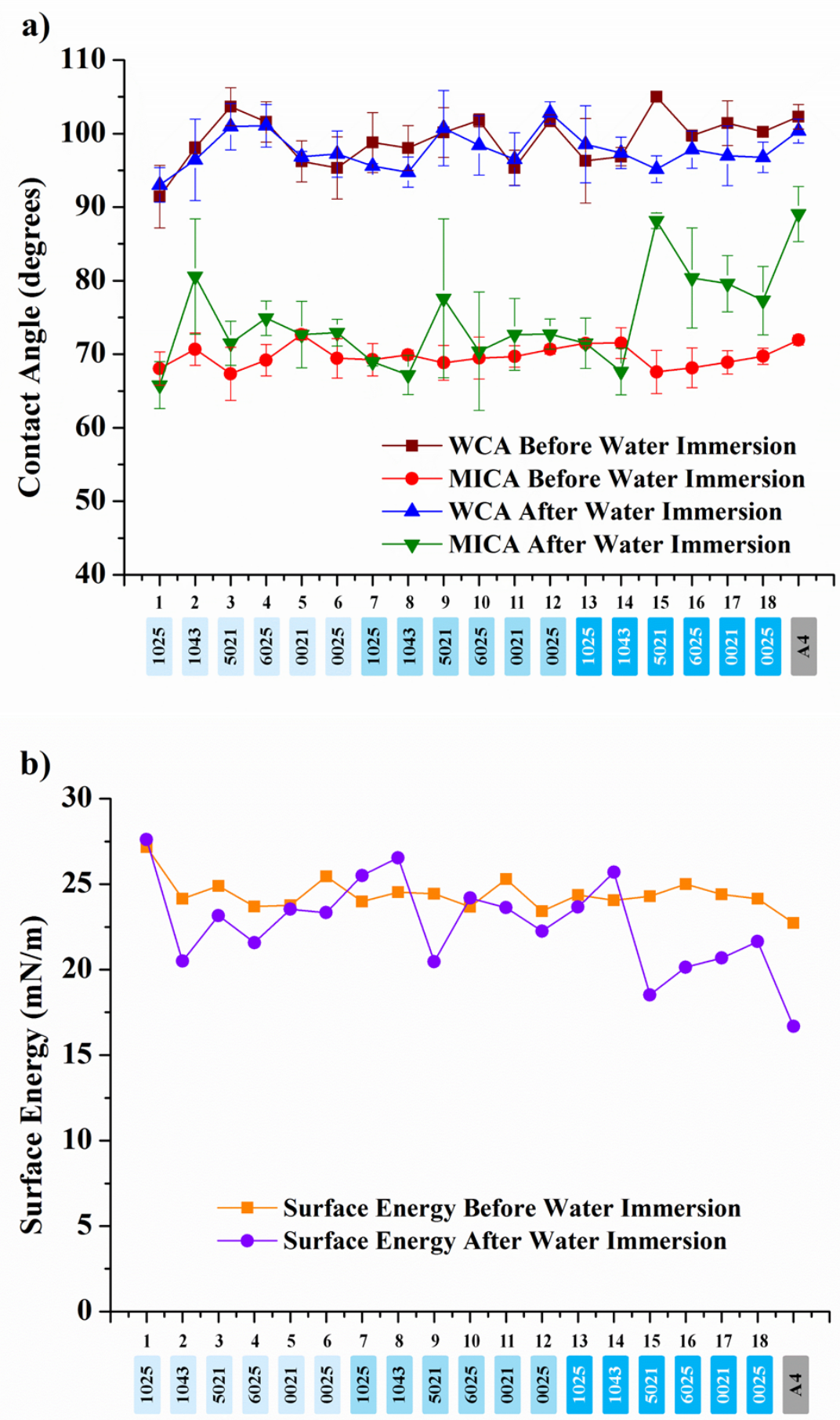

Figure 3: a) Water and methylene iodide contact angles before and after 28 days of water aging. Each data point represents the average and standard deviation of 3 measurements. b) Surface energy of coatings calculated by the Owens-Wendt method utilizing the average WCA and MICA measurements. Coatings labels: Coatings are arranged in the order of increasing phenylmethyl composition of the silicone 
oil (ex: $1-6,7-12,13-18)$ while the darkening of blue shade indicate increasing oil content from 1,2 to $5 \%$ and the controls and standards are shaded in gray.

Figure $4(a, b, c)$ shows the atom concentration change determined using XPS of $\mathrm{Si}, \mathrm{C}, \mathrm{O}$, and $\mathrm{N}$ as a function of etch depth from the coating surface (for coatings A4-20, silicone oil-modified formulation 5 and 17). The depth profiling graph (Figure 4 a.) for SiPU without silicone oil (A4-20) showed about $22 \%$ surface concentration of $\mathrm{Si}$, which gradually decreased and leveled off to $5 \%$ after about $3.5 \mathrm{~nm}$ deep into the coating. For the A4-20 coating, the concentration of $\mathrm{O}$ followed a similar trend as that for $\mathrm{Si}$, yet slightly higher atomic concentration than Si was observed. The results suggest that siloxane was concentrated near the first $3.5 \mathrm{~nm}$ of the surface for A4-20, which was very similar to previous surface characterization of siloxane-PU coatings conducted by Siripirom et al. ${ }^{40}$ In that study it was reported that siloxane-PU formulation with difunctional APT-PDMS has a siloxane layer thickness of about $3.5 \mathrm{~nm}$ when characterized using Rutherford backscattering. The phenylmethyl silicone oil-modified SiPU formulation 5 (Figure 4 b.) showed a similar trend for atomic concentration profiles as A4-20 had a thicker layer of siloxane/silicone oil. For formulation 5, the Si concentration appears to plateau at around $6 \mathrm{~nm}$ from the surface, which was almost double for that of A4-20 without silicone oil. In addition, formulation 5 showed a Si surface concentration of $25-29 \%$, which was slightly higher than that for A4-20. As the phenylmethyl silicone oil concentration was increased from $1 \%$ to $5 \%$, siloxane/silicone oil was predominant up to about $20 \mathrm{~nm}$ deep into the coating (comparing Figure $4 \mathrm{~b}$. and c.). The surface concentration of Si had increased up to $30 \%$ for formulation 17. The increase in thickness of the siloxane layer suggests that the added phenylmethyl silicone oil had segregated closer to the surface along with the siloxane component of the SiPU coating system. 
a)

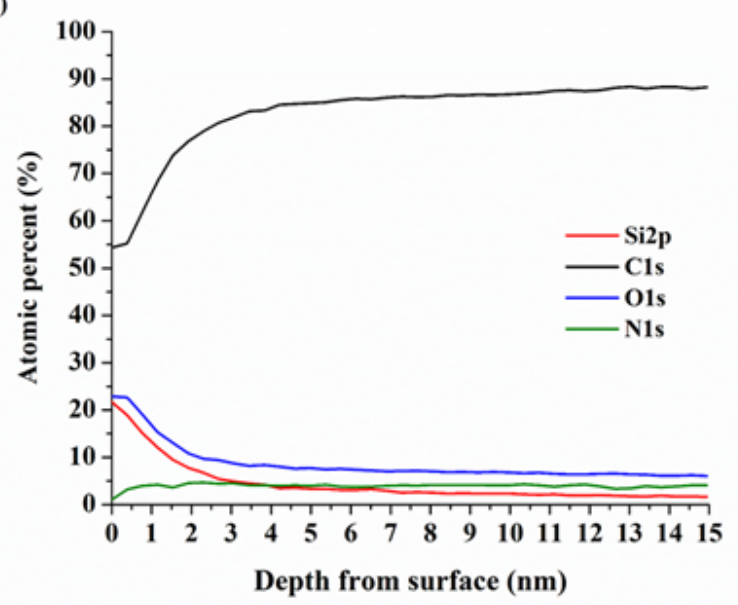

b)

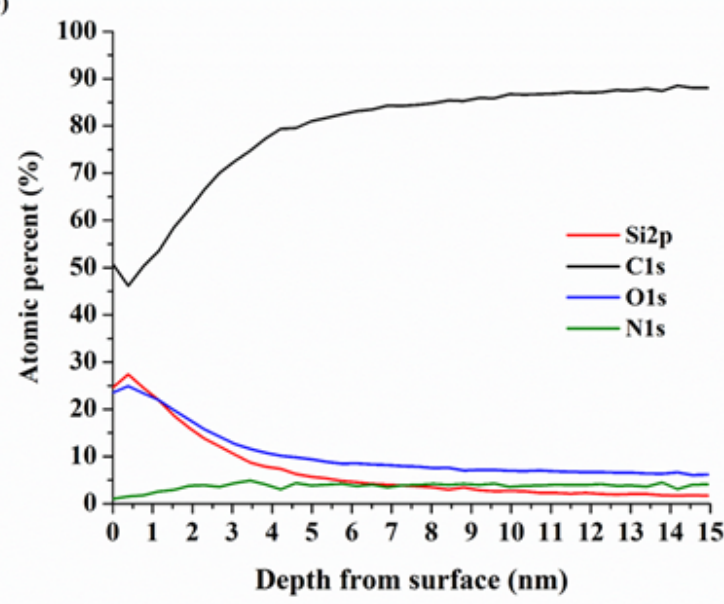

c)

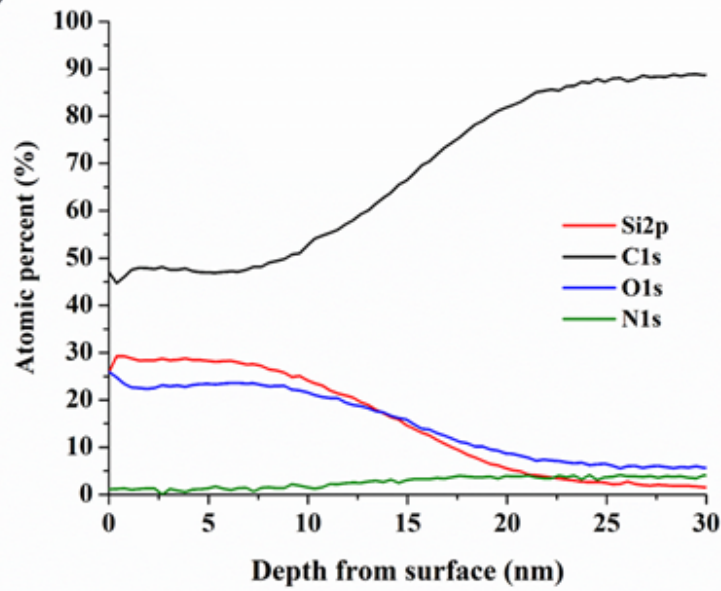

Figure 4: XPS atomic concentration depth profile of a) A4-20 siloxane-PU without oil; b) silicone oilmodified formulation 5; and c) silicone oil-modified formulation 17. 
Laboratory biological assays using single model marine species provide an effective method to quickly screen a range of bench scale marine coating formulations. This method has enabled efficient identification of successful candidate marine coatings formulations without having to expend valuable resources at field testing sites which can be time- and cost-consuming. However, it is widely accepted that field immersion studies represent a more realistic environment in which new marine formulations need to perform in order to enter the marine paint market as a successful product. Therefore, select formulations which performed well during laboratory biological assays were subjected to field immersion studies. Formulation screening conducted using laboratory assays have shown good correlation with field immersion results, indicating the ability to forecast the fouling-release performance and downselect coating candidates before conducting field immersion studies. ${ }^{41}$

Following 28 days of water aging and prior to any biological characterization studies, all experimental, internal control coatings and commercial standards were subjected to leachate toxicity assessments. Leachates (extracts in growth mediums described above) from coatings were collected and measured for growth and compared to positive growth control (fresh nutrient medium). None of the silicone oil-modified coatings displayed toxicity compared to the positive growth control (data not provided).

Ulva linza is present in oceans around the world and it is one of the most common species of green macroalgae that contributes to biofouling on ships' hulls. ${ }^{42}$ It is known that surface wettability plays a key role in both promoting settlement and adhesion strength of $U$. linza. ${ }^{43-45}$ In particular hydrophobic surfaces tend to promote settlement of $U$. linza, whereas spores tend to adhere more strongly to hydrophilic surfaces. Figure 5 shows $U$. linza removal from the experimental, internal control and commercial standard coatings after water-jetting at $9 \mathrm{kPa}$ and $67 \mathrm{kPa}$. ANOVA's conducted for the $U$. linza removal assay suggest that there are coatings within the set from which removal at both water jet pressures were significantly different (p-value $<0.0001$, Tables S2 and S5, included in Supporting Information). Several experimental coatings with silicone oil displayed significantly higher sporeling removal compared to all internal control and commercial standard coatings when subjected to $9 \mathrm{kPa}$ water jet treatment (Figure 5). In particular, a Tukey's comparison test (pairwise comparison) revealed that the phenylmethyl silicone oil-modified coatings, except formulations 11 and 17 , showed significantly higher biomass removal compared to A4-20, 
silicone elastomer (Dow Corning T2), pure polyurethane (PU) and Intersleek® 900 (IS 900) (all pvalues $<0.05$, Table S4). Water-jet treatments conducted at the higher pressure $(67 \mathrm{kPa})$ resulted in more biomass removal from most coatings. Phenylmethyl silicone oil-modified coatings displayed slightly higher removal of sporelings compared to that of A4-20 without silicone oil, yet statistically most experimental coatings were similar in performance against sporeling removal at $67 \mathrm{kPa}$ water-jet pressure (Table S7). However, all silicone oil-modified coatings showed significantly higher sporeling removal when compared to internal controls of T2 and PU and the commercial standard IS 900 (Table S7).

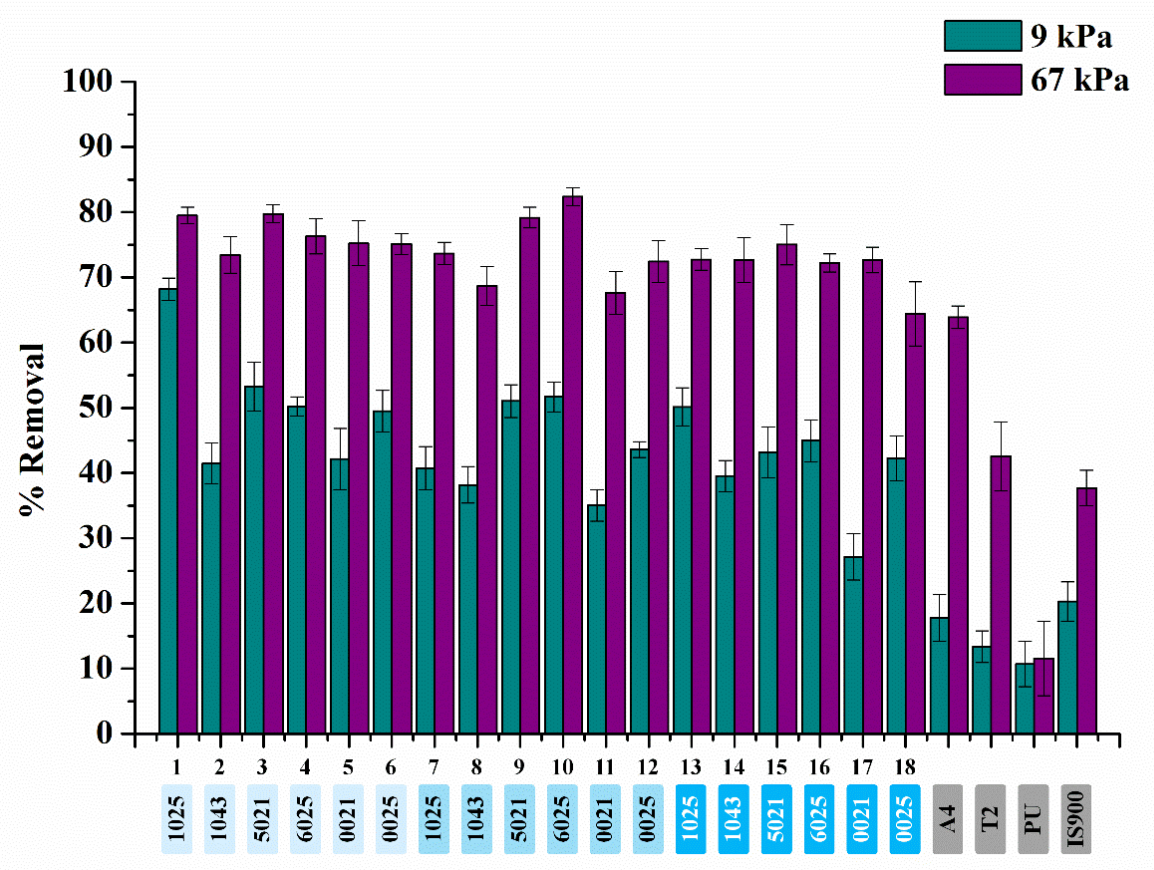

Figure 5: Macroalgae (Ulva linza) removal from experimental and control/standard coatings after water-jet treatment at $9 \mathrm{kPa}$ and $67 \mathrm{kPa}$. Each data point represents the average percent removal value of 6 replicates. Error bars indicate one standard error of the mean. Coatings labels: Coatings are arranged in the order of increasing phenylmethyl composition of the silicone oil (ex: 1-6, 7-12, 13-18) while the darkening of blue shade indicates increasing oil content from 1,2 to $5 \%$ and the controls and standards are shaded in gray.

In general, all of the phenylmethyl silicone oil-modified siloxane-PU coatings showed a high removal of sporelings of $U$. linza upon water-jet treatment (Figure 5). Interestingly, silicone oil-modified experimental 
coatings demonstrated higher removal of sporelings at low water jet pressures $(9 \mathrm{kPa})$ compared to the internal control A4-20 without any oil, which suggests that incorporation of oil improved sporeling removal from the siloxane-PU system. At water-jet treatments of $9 \mathrm{kPa}$ and $67 \mathrm{kPa}$, all silicone oil-modified siloxanePU coatings exceeded the amount of removal observed for the commercial fouling-release coating IS 900 (Figure 5, and Table S4,S7). Experimental coating formulations 1, 3, 9 and 10 exhibited good foulingrelease performance towards sporelings of $U$. linza at both water jet pressures with percent removal values as high as $\sim 75-80 \%$ (Figure 5). These coatings showed statistically higher removal of sporelings of $U$. linza than standard IS 900 and the internal controls, T2 and PU at $95 \%$ significance level (all p-values $<0.05$, Table S3 and S6). Therefore, silicone oil-incorporated coatings seem to impart good fouling-release properties towards $U$. linza. It is apparent that self-segregated silicone oil may lead to weaker attachment allowing higher biomass removal at low water jet pressure. Greater removal of U.linza has been observed with coating surfaces having low SE (ex. PDMS) while removal was extremely poor for those with high SE. ${ }^{46}$ It is proposed that the adhesive secreted by the spores spreads more on hydrophilic surfaces covering a greater surface area compared to that on hydrophobic surfaces which leads to easy release when subjected to stress or shear force. The SE of the silicone oil-modified coatings indicates a hydrophobic surface (Figure 3 b.), thus fouling-release trends for U.linza are in agreement with well-accepted studies. Additionally, interfacial slippage introduced by the silicone oil enhanced the easy release of green algae, as fouling-release performance of experimental coatings were significantly superior at very low water-jet pressure $(9 \mathrm{kPa})$ compared to all other coatings. Specifically, silicone oils with $40-60 \%$ phenylmethyl content provided the best sporeling release performance at 1-2\% oil level (Table S3 and S6).

With respect to the diatom $N$. incerta, the pure polyurethane internal control (PU) and IS 900 standard displayed the highest amount of cell removal (Figure 67). Pure polyurethane, which does not contain any PDMS, exhibited more than $90 \%$ N. incerta removal. However, all silicone oil-modified coatings displayed impaired removal of $N$. incerta when compared to the A4-20 internal control. The observed results can be explained when one considers the adhesion preference of this diatom strain, which typically adheres more strongly to hydrophobic surfaces than to hydrophilic surfaces (a behavior that is the exact opposite of green algae U.linza). ${ }^{44,}{ }^{47}$ Contact angle and SE measurements for silicone oil-modified SiPU coatings indicate hydrophobic surface characteristics (Figure 3 a. and b.). Therefore, diatom removal was negatively affected, 
which is not unexpected. Coatings which displayed good fouling-release performance towards $U$. linza (1, 3,9 and 10) performed rather poorly towards $N$. incerta highlighting the complexity of attaining a foulingrelease surface which performs well for a variety of organisms. The high amount of cell removal observed for IS 900 is attributed to its reported amphiphilic character. The $1^{\text {st }}$ generation SiPU formulation showed N. incerta removal comparable to Intersleek $₫ 700$ and T2 silicone elastomer. Interestingly, however, the experimental coatings modified with phenylmethyl homopolymer oil (100\% phenylmethyl) showed similar N. incerta removal at all oil levels $(1,2$, and $5 \%)$.

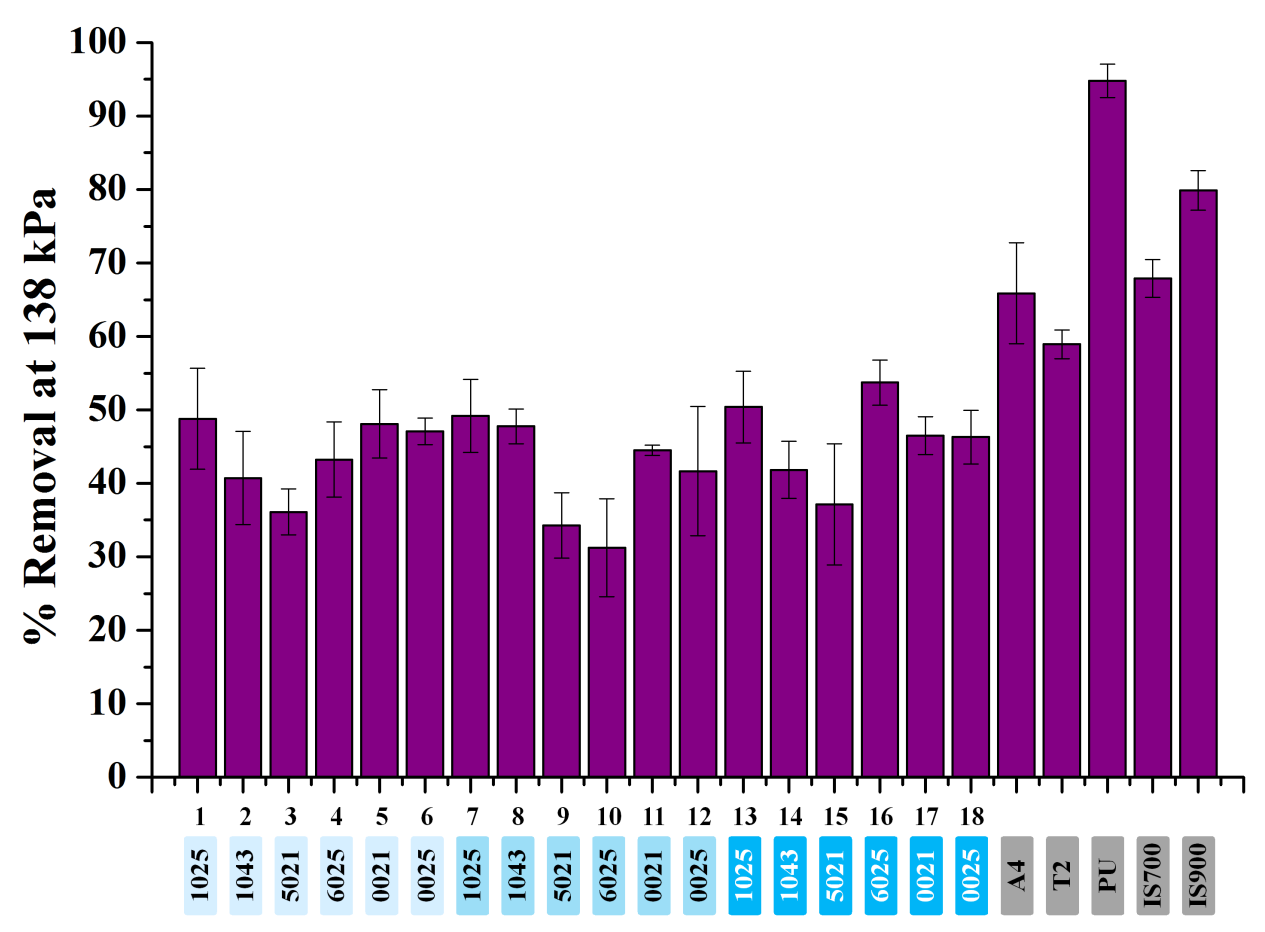

Figure 6: Diatom (Navicula incerta) removal from experimental and control/standard coatings after treatments with a $138 \mathrm{kPa}(20 \mathrm{psi})$ water jet pressure for $10 \mathrm{~s}$ seconds. Each percent removal value represents the average of 3 replicates samples. Error bars indicate one standard deviation of the mean. Coatings labels: Coatings are arranged in the order of increasing phenylmethyl composition of the silicone oil (ex: $1-6,7-12,13-18)$ while the darkening of blue shade indicates increasing oil content from 1,2 to $5 \%$ and the controls and standards are shaded in gray. 
Statistical analysis of silicone oil-modified experimental coatings revealed those with significantly different performance towards diatom removal at $138 \mathrm{kPa}$ water jet treatment ( $\mathrm{p}$-value $<0.0001$, Table S8). Tukey's comparison showed that SiPU without silicone oil (A4-20) has similar diatom removal performance to that of IS 700, IS 900 and silicone elastomer T2. Even though a few experimental coatings display impaired diatom removal, coatings $1,7,13$, and 16 (best performers out of experimental coatings) are statistically similar in performance to the A4-20 formulation at $\alpha=0.05$ significance level (Table S9). On the other hand, they also showed comparable performance to Dow Corning T2 silicone elastomer in regard to $N$. incerta removal (Table S9). Coatings 16 and 13 also showed comparable $N$. incerta removal performance to IS 700 although most of the other experimental coatings showed slightly impaired performance compared to IS 700. In general, coatings with silicone oils, which contain low phenylmethyl compositions seemed to provide the best performance against slime forming diatoms.

Marine bacterium Cellulophaga lytica biofilm removal from coatings after exposure to $69 \mathrm{kPa}(10 \mathrm{psi})$ water jet treatment is shown in Figure 7. Statistical analysis on biofilm removal data for experimental coatings showed that there are formulations with statistically different biofilm removal properties ( $p$-value $<0.0001$, Table S11). The commercial fouling release-coating IS 900 outperformed all of the experimental coatings in terms of biofilm removal $(97 \%)$, including the five best performing silicone oil-modified coatings $(1,5,8$, 16, and 17) observed in this particular assay (Table S12). However, several siloxane PU-coatings modified with phenylmethyl silicone oils showed a similar degree of biofilm removal as the IS 700 standard. Coating 1 with $1 \%$ of PMM1025 silicone oil showed the greatest removal $(72 \%)$ of bacterial biofilm out of all the experimental coatings, and at $\alpha=0.05$ significance level, this formulation also outperformed IS 700 ( $p$-value $<0.05$, Table S12 and S13). On the other hand, the five best experimental coatings displayed similar bacterial biofilm removal performance to A4-20, Dow Corning T2 and pure polyurethane control coatings (all p-values are $>0.05$, Table S12 and S13). In general, the incorporation of phenylmethyl silicone oil did not affect the bacterial biofilm removal properties of the siloxane-PU system since several experimental coatings showed similar performance to the A4-20 internal control. No significant trend was observed with regard to phenylmethyl composition of silicone oils in this assay. 


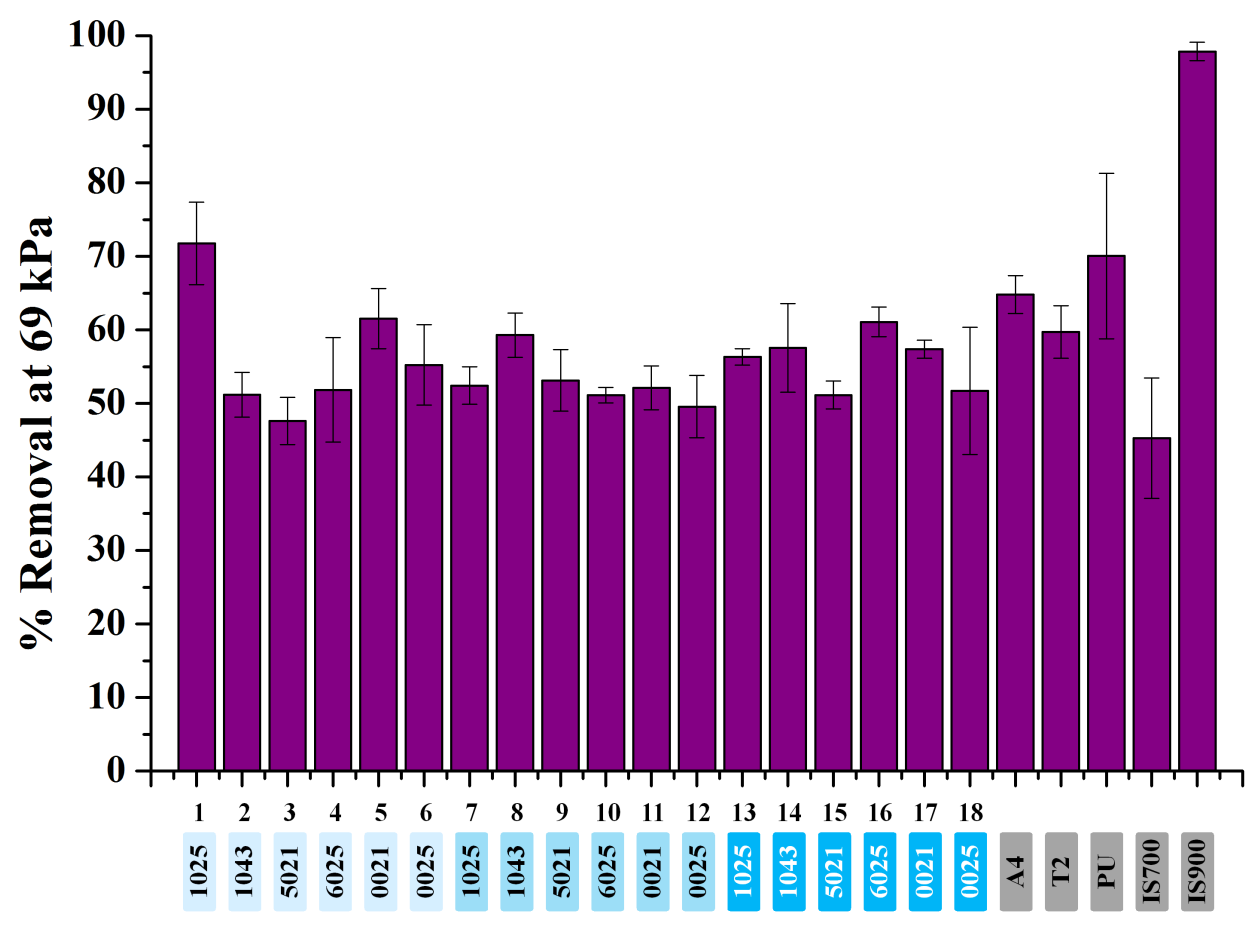

Figure 7: Bacterial (Cellulophaga lytica) biofilm removal from experimental and control/standard coatings after being exposed to a $69 \mathrm{kPa}(10 \mathrm{psi})$ water-jet treatment for $5 \mathrm{~s}$. The percent removal values represent the average of 3 replicate samples. Error bars indicate one standard deviation of the mean. Coatings labels: Coatings are arranged in the order of increasing phenylmethyl composition of the silicone oil (ex: 1$6,7-12,13-18$ ) while the darkening of blue shade indicates increasing oil content from 1,2 to $5 \%$ and the controls and standards are shaded in gray.

Macrofouling organisms are the main culprits of heavy calcareous fouling which leads to increased hull roughness and severe powering penalties. ${ }^{48}$ Barnacle cyprids are known to conduct surface exploration before permanently cementing themselves (a process known as metamorphism). ${ }^{49-50}$ Like other marine organisms, barnacles also display species specific adhesion preferences according to surface chemistry and wettability. ${ }^{49}$ Therefore, barnacle adhesion strength to silicone oil-modified coatings reflect the surface properties of these coatings. Figure 8 shows the adhesion strength measurements of adult barnacles that were reattached to the experimental and control/standard coatings. During this test, reattached barnacles were pushed off in shear using a force gauge. If the barnacle is adhered weakly, the barnacle will release 
without any damage. Strongly adhered barnacles would break during the test indicating poor foulingrelease. For a good fouling-release coating, the adhesion strength of barnacles should be minimal and have several non-attached barnacles. Poor fouling-release surfaces show high adhesion strength of barnacles and multiple broken barnacles.

$* * *$ All barnacles broke

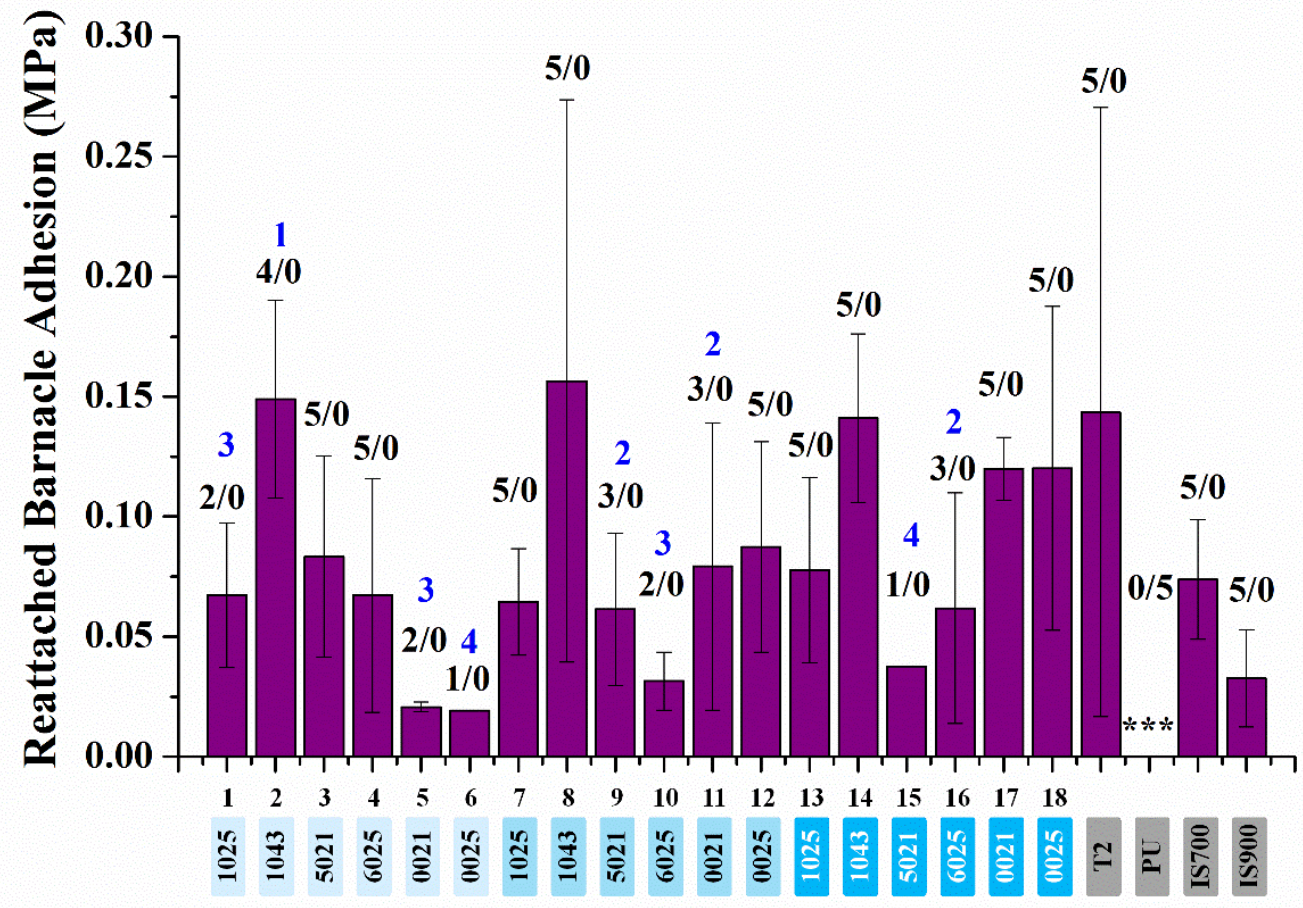

Figure 8: Adhesion of reattached barnacle (Amphibalanus amphitrite) experimental and control coatings. Five adult barnacle reattachments were attempted for each coating. Each adhesion strength value represents the average of total number of reattached barnacles released without damage. Error bars represent the standard deviation of average barnacle release stress. The ratio represents the number of measured barnacles over the number of broken/damaged barnacles. The blue digits represent the number of non-attached barnacles. Coatings labels: Coatings are arranged in the order of increasing phenylmethyl composition of the silicone oil (ex: 1-6, 7-12, 13-18) while the darkening of blue shade indicate increasing oil content from 1, 2 to $5 \%$ and the controls and standards are shaded in gray. 
All five barnacles reattached onto the pure polyurethane surface exhibited base/shell plate damage during push off measurements, indicating its poor fouling-release properties. Adhesion strength values of approximately $0.10-0.15 \mathrm{MPa}$ were observed for the $1^{\text {st }}$ generation SiPU coating. ${ }^{14}$ Several of the silicone oil-modified siloxane-PU coatings showed comparable or better fouling-release properties than IS 900 in this category. Several of the experimental coatings also had several non-attached barnacles suggesting excellent performance against barnacle adhesion.

In order to conduct statistical analysis of data obtained from barnacle adhesion assay, a scoring system was introduced as explained in statistical analysis section. According to this scoring system non-attached barnacles were regarded as 100 and the highest adhesion strength was regarded as score of 0 . ANOVA of the adhesion data converted to scores indicated that the coatings display significantly different adhesion strengths of reattached barnacles (Table S14). Barnacle adhesion strengths of several experimental coatings (Table S15; coatings $1,5,6,10$, and 15) were similar to that of IS 900 and IS 700 although significantly better than Dow T2 silicone elastomer. Barnacles (A.amphitrite) adhered to low SE coatings have shown low critical removal stress; indicative of good fouling-release properties of low SE materials towards barnacles. ${ }^{51}$ Coatings discussed here (silicone oil-modified SiPU coatings) have SE in the range of $20-25 \mathrm{mN} / \mathrm{m}$, therefore providing low adhesion strength for barnacles. A decrease in barnacle adhesion and an increase in the number of non-attached barnacles were observed with a low amount (1wt \%) of phenylmethyl homopolymer oil, whereas a similar effect was obtained with slightly higher amounts of phenylmethyl copolymer oil suggesting a correlation between phenylmethyl composition and barnacle adhesion. Overall, siloxane-PU coatings displayed comparable barnacle release performance to the commercial fouling-release coatings.

Mussels are fairly large fouling animals which tend to attach to substrate with the use of multiple byssal threads. Several studies have shown that amino acid 3,4-dihydroxyphenyl-L-alanine (DOPA) plays a key role in producing adhesive plaque during mussel attachment to a substrate ${ }^{52}$ Studies have also shown that mussel adhesive plaque spreads the least on low SE surfaces (such as PTFE) and requires more byssal threads to attach to the surface ${ }^{52}$ However, the exact opposite behavior is observed for hydrophilic surfaces. Figure 9 provides the results from the mussel adhesion experiment. Several siloxane-PU coatings 
had no mussel attachment during the 3-day attachment test. However, a few coatings with phenylmethyl silicone oil displayed minimal mussel attachment where the mussels were released with very low forces. This observation is in agreement with previous findings on the preference of mussel adhesion behavior, where significantly low mussel adhesion strengths were observed for low SE materials. Control coating A420 and the IS 900 standard did not enable any mussels to attach to their respective surfaces, which may imply that these coatings perform well against mussel settlement. The viscosity of the silicone oil additive seems to play an important role in the case of mussel adhesion. Interestingly, the experimental coatings which did not enable any mussels to attach contained phenylmethyl silicone oils with similar viscosities, regardless of phenylmethyl composition. It may be hypothesized that the silicone oils with similar viscosity have enough mobility to self-stratify to the surface. Statistical analysis was not performed due to numerous data points with no mussel attachment.

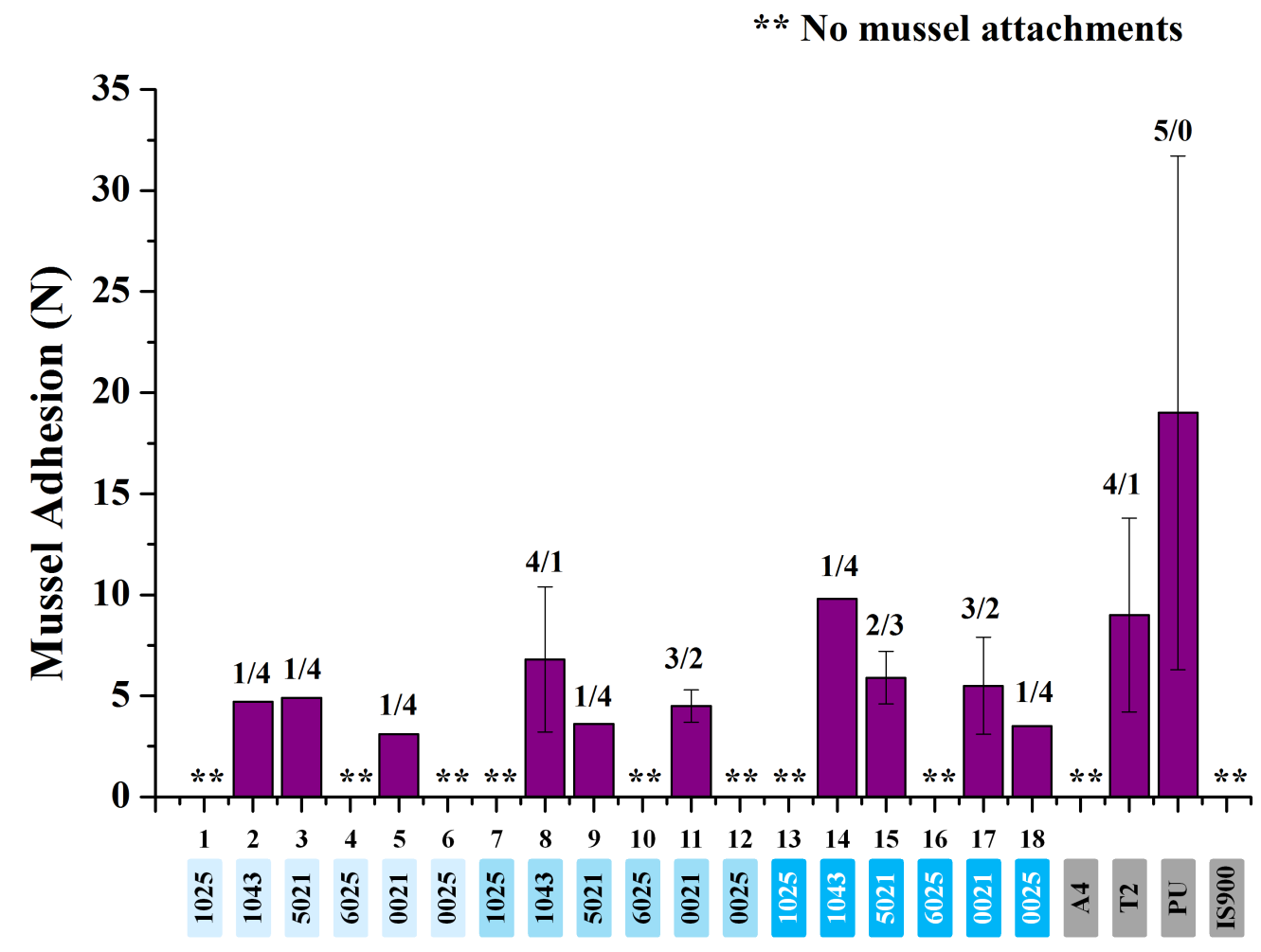

Figure 9: Adhesion of mussels (Geukensia demissa) to experimental and control coatings. Five mussels were introduced to each coating. Each adhesion strength value represents the average of total number of attached mussels released from the surface. Error bars represent the standard deviation of the average 
adhesion force. The ratio represents the number of attached mussels over the number of non-attached mussels. ${ }^{* *}$ indicate the coatings that did not have any attached mussels. Coatings labels: Coatings are arranged in the order of increasing phenylmethyl composition of the silicone oil (ex: 1-6, 7-12, 13-18) while the darkening of blue shade indicates increasing oil content from 1, 2 to $5 \%$ and the controls and standards are shaded in gray.

Coatings which demonstrated overall good fouling-release properties during laboratory biological assays were down selected for field immersion testing. Coating formulations 5 and 6 were selected since they had the lowest barnacle adhesion (with several barnacles not adhering at all), and good release properties for Ulva and C. lytica. Included in the field test were also control coatings A4-20 and IS 900 . Figure 10 shows the visual appearance of the panels before and after water-jet cleaning at the indicated pressures (i.e., 0.69 and $1.65 \mathrm{MPa}$ ). After 3 months of field immersion in Hawaii, the two experimental coatings showed qualitatively similar fouling-release performances to the SiPU control and commercial standard. As the coatings were exposed for a longer duration, the effects of incorporating silicone oil can be observed. Specifically, after 11 months of exposure at the Morro Bay testing site in California, coating 5 (containing silicone oil PMM-0021) outperformed the internal control A4-20 and displayed similar fouling-release performance to the commercial standard IS 900 . The oil in coating 5 has a lower molecular weight and viscosity than the one used in coating 6 and may contribute more effectively to interfacial slippage. After 11 months of exposure in Singapore, Formulation 5 showed comparable performance to A4-20 slightly edging over formulation 6 . However, it is worth noting that a lower water-jet pressure was used at the Singapore test site. Variations in the marine environments in these different bodies of water could contribute to the observed trend in fouling-release properties of formulations 5 and 6 . In the past, studies have shown that oceanic conditions vary quite a bit based on their location. ${ }^{53-54}$ Although it is well recognized that different sea water parameters such as temperature, salinity, density, and $\mathrm{pH}$ have an influence over biofouling, little attention has been given to understand their exact effects. ${ }^{1}$ 


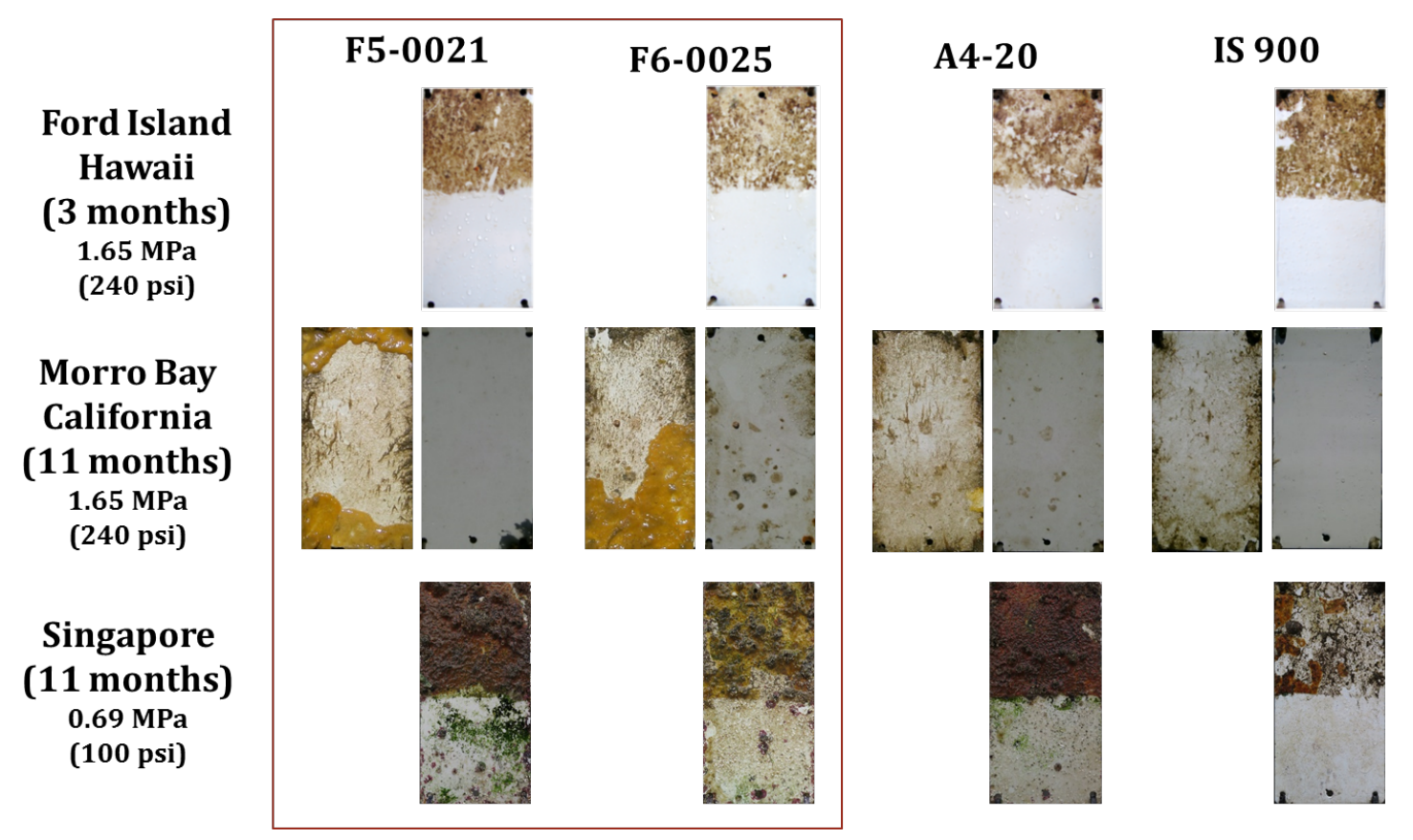

Figure 10: Visual appearance of coatings included in field immersion trials at California, Singapore and Hawaii test sites. In Hawaii and Singapore test sites, half of each panel was subjected to water jet cleaning while the other half represents the accumulated fouling. At the California test site, the entire panel was subjected to water jet treatment. Thus the picture on the left $\left(2^{\text {nd }}\right.$ row) represent the accumulated fouling while picture on the right represent the coating after cleaning.

Incorporation of phenylmethyl silicone oil into siloxane-PU coatings has been shown to improve the foulingrelease performance towards macrofouling organisms during laboratory biological assay tests; in particular, for macroalgae sporeling release, where coatings with silicone oils containing $<60 \%$ phenylmethyl composition showed significantly better performance than the SiPU control and commercial standards. Coatings modified with $1 \%$ of silicone oils PMM-0021 and PMM-0025 (phenylmethyl homopolymer) showed reduced barnacle adhesion. For phenylmethyl copolymer oils PMM-5021 and PMM-6025, low barnacle adhesion strength was observed with slightly higher oil amount ( $2 \%$ or $5 \%$ by wt.). Several silicone oil-modified coatings showed excellent fouling-release performance towards marine mussels where the SiPU coatings that did not allow any mussels to adhere to their surface contained phenylmethyl silicone oils with a viscosity of $500 \mathrm{cs}$. However, silicone oil incorporation did not seem to substantially affect the bacterial biofilm and microalgae removal properties compared to the SiPU formulation without silicone oil 
(A4-20). The field immersion studies showed that incorporating small amounts of phenylmethyl silicone oil could enhance the fouling-release properties of SiPU coatings.

\section{Conclusions}

Previous studies had suggested that inclusion of phenylmethyl silicone oil in silicone elastomer-based fouling-release coatings led to improved fouling-release performance. ${ }^{15-22}$ These improvements were reasoned by hypothesizing that the reduced adhesion strength of marine organisms was due to increased interfacial slippage induced by the exuding silicone oil. This study investigated the effects of incorporating phenylmethyl silicone oils in a SiPU fouling-release coating system. Contact angle and surface energy measurements suggested that the coating surfaces were hydrophobic and remained hydrophobic after 1 month of water immersion. XPS analysis was helpful to understand the effects of silicone oil on coating morphology and indicated that stratification of the silicone oil occurred along with siloxane and formed a thicker interfacial layer. Laboratory biological assays indicated that an improvement in release properties for several types of model fouling organisms might have reflected the silicone oil modification. Siloxane-PU coatings modified with silicone oils demonstrated excellent release properties against the macroalga $U$. linza; high removal was observed at low water-jet pressures. An improvement in lower adhesion strength of macrofouling organisms was also observed with incorporation of silicone oil. In particular, silicone oils with high phenylmethyl composition provided good fouling-release performance towards barnacles $(A$. amphitrite). Excellent fouling-release performance towards marine mussels ( $G$. demissa) was observed for coatings containing phenylmethyl silicone oil with an approximate viscosity of $500 \mathrm{cs}$, regardless of oil type or composition. However, fouling-release performance towards diatoms (N. incerta) and bacteria (C. lytica) was largely unaffected by silicone oil modification into SiPU coating system. Selected phenylmethyl silicone

oil-modified siloxane-PU coatings also displayed long-term fouling-release performance comparable to commercial IS 900 standard during field immersion tests at three different test sites.

\section{Acknowledgements}

This work was supported by the Office of Naval Research [grant number N00014-12-1-0482, North Dakota State University], [grant numbers N00014-13-1-0633 and N00014-13-1-0634, University of Newcastle], [grant number N00014-15-1-2685, University of Hawaii], [grant number N00014-12-1-0432, California 
Polytechnic State University]. The authors would also like to thank Kenneth Anderson and Gregory Strommen for their help with XPS experiments.

\section{Supporting Information}

Table S1 includes the film thickness of coatings used for XPS analysis. Tables S2 through S16 showing the statistical analysis of the laboratory fouling-release assays are provided as Supporting Information.

\section{References}

1. Yebra, D. M.; Kiil, S. K.; Dam-Johansen, K., Antifouling Technology_Past, Present and Future Steps Towards Efficient and Environmentally Friendly Antifouling Coatings. Progress in Organic Coatings 2004, 50 (2), 75-104.

2. Callow, J. A.; Callow, M. E., Trends in the Development of Environmentally Friendly FoulingResistant Marine Coatings. Nat Commun 2011, 2, 244.

3. Lejars, M.; Margaillan, A.; Bressy, C., Fouling Release Coatings: A Nontoxic Alternative to Biocidal Antifouling Coatings. Chemical Reviews 2012, 112 (8), 4347-4390.

4. Magin, C. M.; Cooper, S. P.; Brennan, A. B., Non-Toxic Antifouling Strategies. Materials Today 2010, $13(4), 36-44$.

5. Callow, M. E.; Callow, J. A., Marine Biofouling: A Sticky Problem. Biologist 2002, 49 (1), 10.

6. Genzer, J.; Efimenko, K., Recent Developments in Superhydrophobic Surfaces and Their Relevance to Marine Fouling: A Review. Biofouling 2006, 22 (5), 339-360.

7. Dafforn, K. A.; Lewis, J. A.; Johnston, E. L., Antifouling Strategies: History and Regulation, Ecological Impacts and Mitigation. Marine Pollution Bulletin 2011, 62 (3), 453-465.

8. Konstantinou, I. K.; Albanis, T. A., Worldwide Occurrence and Effects of Antifouling Paint Booster Biocides in the Aquatic Environment: A Review. Environment International 2004, 30 (2), 235-248.

9. $\quad$ Adkins, J. D.; Mera, A. E.; Roe-Short, M. A.; Pawlikowski, G. T.; Brady Jr, R. F., Novel Non-Toxic Coatings Designed to Resist Marine Fouling. Progress in Organic Coatings 1996, 29 (1-4), 1-5.

10. Brady, R. F., Jr., Clean Hulls without Poisons: Devising and Testing Nontoxic Marine Coatings. Journal of Coatings Technology 2000, 72 (900), 45-56.

11. Webster, D. C.; Ekin, A. Functionalized Polysiloxane Polymers. US7799434 B2, 2010.

12. Sommer, S. A.; Joseph, B. R.; Fischer, H. D.; Bodkhe, R. B.; Staflien, S. J.; Daniels, J.; Yehle, C.; Webster, D. C., Effect of Pigmentation on Siloxane-Polyurethane Coatings. Journal of Coatings Technology Research 2011, 8 (6), 661-670.

13. Sommer, S.; Ekin, A.; Webster, D. C.; Stafslien, S. J.; Daniels, J.; VanderWal, L. J.; Thompson, S. E. M.; Callow, M. E.; Callow, J. A., A Preliminary Study on the Properties and Fouling-Release Performance of Siloxane-Polyurethane Coatings Prepared from Pdms Macromers. Biofouling 2010, 26 (8), 961-972. 
14. Bodkhe, R. B.; Thompson, S. E. M.; Yehle, C.; Cilz, N.; Daniels, J.; Stafslien, S. J.; Callow, M. E.; Callow, J. A.; Webster, D. C., The Effect of Formulation Variables on Fouling-Release Performance of Stratified Siloxane-Polyurethane Coatings. Journal of Coatings Technology Research 2012, 9 (3), 235-249.

15. Truby, K.; Wood, C. D.; Stein, J.; Cella, J.; Carpenter, J.; Kavanagh, C.; Swain, G.; Wiebe, D.; Lapota, D.; Meyer, A.; Holm, E.; Wendt, D.; Smith, C.; Montemarano, J., Evaluation of the Performance Enhancement of the Silicone Biofouling-Release Coatings by Oil Incorporation. Biofouling 2000, 15 (1-3), 141-150.

16. Miline, A. Anti-Fouling Marine Compositions. US 4025693, May 24, 1977.

17. Miline, A. Coated Marine Surfaces. UK 1470465, 1977.

18. Edwards, D. P.; Nevell, T. G.; Plunkett, B. A.; Ochiltree, B. C., Resistance to Marine Fouling of Elastomeric Coatings of Some Poly (Dimethylsiloxanes) and Poly (Dimethyldiphenyl-Siloxanes). International Biodeterioration \& Biodegradation 1994, 34, 349-359.

19. Nevell, T. G.; Edwards, D. P.; Davis, A. J.; Pullin, R. A., The Surface Properties of Silicone Elastomer Exposed to Sea Water. Biofouling 1996, 10, 199-212.

20. Newby, B.; Chaudhury, M.; Brown, H., Macroscopic Evidence of the Effect of Interfacial Slippage on Adhesion. Science 1995, 269, 1407-109.

21. Stein, J.; Truby, K.; Wood, C. D.; Takemori, M.; Vallance, M.; Swain, G.; Kavanagh, C.; Kovach, B.; Schultz, M.; Wiebe, D.; Holm, E.; Montemarano, J.; Wendt, D.; Smith, C.; Meyer, A., Structure-Property Relationships of Silicone Biofouling-Release Coatings: Effect of Silicone Network Architecture on Pseudobarnacle Attachment Strengths. Biofouling 2003, 19 (2), 87-94.

22. Stein, J.; Truby, K.; Wood, C. D.; Stein, J.; Gardner, M.; Swain, G.; Kavanagh, C.; Kovach, B.; Schultz, M.; Wiebe, D.; Holm, E.; Montemarano, J.; Wendt, D.; Smith, C.; Meyer, A., Silicone Foul Release Coatings: Effect of the Interaction of Oil and Coating Functionalities on the Magnitude of Macrofouling Attachment Strengths. Biofouling 2003, 19, 71-82.

23. Pieper, R. J.; Ekin, A.; Webster, D. C.; Casse, F.; Callow, J. A.; Callow, M. E., A Combinatorial Approach to Study the Effect of Acrylic Polyol Composition on the Properties of Crosslinked SiloxanePolyurethane Fouling-Release Coatings. Journal of Coatings Technology Research 2007, 4 (4), 453-461.

24. Stafslien, S. J.; Bahr, J. A.; Feser, J. M.; Weisz, J. C.; Chisholm, B. J.; Ready, T. E.; Boudjouk, P., Combinatorial Materials Research Applied to the Development of New Surface Coatings I: A multiwell plate screening method for the High-Throughput Assessment of Bacterial Biofilm Retention on Surfaces. Journal of Combinatorial Chemistry 2006, 8 (2), 156-162.

25. Ekin, A.; Webster, D. C., Combinatorial and High-Throughput Screening of the Effect of Siloxane Composition on the Surface Properties of Crosslinked Siloxane-Polyurethane Coatings. Journal of Combinatorial Chemistry 2006, 9 (1), 178-188.

26. Owens, D. K.; Wendt, R. C., Estimation of the Surface Free Energy of Polymers. Journal of Applied Polymer Science 1969, 13 (8), 1741-1747.

27. Casse, F.; Ribeiro, E.; Ekin, A.; Webster, D. C.; Callow, J. A.; Callow, M. E., Laboratory Screening of Coating Libraries for Algal Adhesion. Biofouling 2007, 23 (3/4), 267-276.

28. Stafslien, S. J.; Bahr, J. A.; Daniels, J. W.; Wal, L. V.; Nevins, J.; Smith, J.; Schiele, K.; Chisholm, B., Combinatorial Materials Research Applied to the Development of New Surface Coatings Vi: An 
Automated Spinning Water Jet Apparatus for the High-Throughput Characterization of Fouling-Release Marine Coatings. Review of Scientific Instruments 2007, 78 (7), 072204.

29. Cassé, F.; Stafslien, S. J.; Bahr, J. A.; Daniels, J.; Finlay, J. A.; Callow, J. A.; Callow, M. E., Combinatorial Materials Research Applied to the Development of New Surface Coatings V. Application of a Spinning Water-Jet for the Semi-High Throughput Assessment of the Attachment Strength of Marine Fouling Algae. Biofouling 2007, 23 (2), 121-130.

30. Callow, M. E.; Callow, J. A.; Conlan, S.; Clare, A. S.; Stafslien, S., Efficacy Testing of Nonbiocidal and Fouling-Release Coatings. In Biofouling Methods, John Wiley \& Sons, Ltd: 2014; pp 291-316.

31. Stafslien, S.; Daniels, J.; Mayo, B.; Christianson, D.; Chisholm, B.; Ekin, A.; Webster, D.; Swain, G., Combinatorial Materials Research Applied to the Development of New Surface Coatings. Iv: A HighThroughput Bacterial Retention and Retraction Assay for Screening Fouling-Release Performance of Coatings. Biofouling 2007, 23 (1), 45-54.

32. Stafslien, S.; Daniels, J.; Bahr, J.; Chisholm, B.; Ekin, A.; Webster, D.; Orihuela, B.; Rittschof, D., An Improved Laboratory Reattachment Method for the Rapid Assessment of Adult Barnacle Adhesion Strength to Fouling-Release Marine Coatings. Journal of Coatings Technology and Research 2012, 9 (6), 651-665.

33. Rittschof, D.; Orihuela, B.; Stafslien, S.; Daniels, J.; Christianson, D.; Chisholm, B.; Holm, E., Barnacle Reattachment: A Tool for Studying Barnacle Adhesion. Biofouling 2008, 24 (1), 1-9.

34. Emily, C. B.; John, M. G., Strategies for Life in Flow: Tenacity, Morphometry, and Probability of Dislodgment of Two Mytilus Species. Marine Ecology Progress Series 1997, 159, 197-208.

35. Burkett, J. R.; Wojtas, J. L.; Cloud, J. L.; Wilker, J. J., A Method for Measuring the Adhesion Strength of Marine Mussels. The Journal of Adhesion 2009, 85 (9), 601-615.

36. Crisp, D. J.; Walker, G.; Young, G. A.; Yule, A. B., Adhesion and Substrate Choice in Mussels and Barnacles. Journal of Colloid and Interface Science 1985, 104 (1), 40-50.

37. Emily Ralston and Geoffrey, S., Bioinspiration-the Solution for Biofouling Control? Bioinspiration \& Biomimetics 2009, 4 (1), 015007.

38. Scardino, A. J.; de Nys, R., Mini Review: Biomimetic Models and Bioinspired Surfaces for Fouling Control. Biofouling 2011, 27 (1), 73-86.

39. Hellio, C.; Yebra, D. M., Advances in Marine Antifouling Coatings and Technologies. Woodhead Publishing Limited: Cambridge, UK, 2009.

40. Siripirom, C. High-Throughput Methods for Characterizing the Mechanical Properties of Coatings. North Dakota State University, Fargo, 2012.

41. Stafslien, S. J.; Sommer, S.; Webster, D. C.; Bodkhe, R.; Pieper, R.; Daniels, J.; Vander Wal, L.; Callow, M. C.; Callow, J. A.; Ralston, E.; Swain, G.; Brewer, L.; Wendt, D.; Dickinson, G. H.; Lim, C.-S.; Teo, S. L.-M., Comparison of Laboratory and Field Testing Performance Evaluations of SiloxanePolyurethane Fouling-Release Marine Coatings. Biofouling 2016, 32 (8), 949-968.

42. Hoipkemeier-Wilson, L.; Schumacher, J. F.; Carman, M. L.; Gibson, A. L.; Feinberg, A. W.; Callow, M. E.; Finlay, J. A.; Callow, J. A.; Brennan, A. B., Antifouling Potential of Lubricious, Micro-Engineered, Pdms Elastomers against Zoospores of the Green Fouling Alga Ulva (Enteromorpha). Biofouling 2004, 20 (1), 53-63. 
43. Callow, M. E.; Callow, J. A.; Ista, L. K.; Coleman, S. E.; Nolasco, A. C.; Lopez, G. P., Use of Self Assembled Monolayers of Different Wettabilities to Study Surface Selection and Primary Adhesion Processes of Green Algae (Enteromorpha) Zoosporesuse of Self Assembled Monolayers of Different Wettabilities to Study Surface Selection and Primary Adhesion Processes of Green Algae (Enteromorpha) Zoospores. Applied and Enviornmental Microbiology 2000, 66 (8), 3249-3254.

44. Finlay, J. A.; Callow, M. E.; Ista, L. K.; Lopez, G. P.; Callow, J. A., The Influence of Surface Wettability on the Adhesion Strength of Settled Spores of the Green Alga Enteromorpha and the Diatom Amphora. Integrative and Comparative Biology 2002, 42 (6), 1116-1122.

45. Callow, J. A.; Callow, M. E.; Ista, L. K.; Lopez, G.; Chaudhury, M. K., The Influence of Surface Energy on the Wetting Behavior of the Spore Adhesive of Marine Alga Ulva Linza. Journal of Royal Society Interface 2005, 2, 319-325.

46. Krishnan, S.; Wang, N.; Ober, C. K.; Finlay, J. A.; Callow, M. E.; Callow, J. A.; Hexemer, A.; Sohn, K. E.; Kramer, E. J.; Fischer, D. A., Comparison of the Fouling Release Properties of Hydrophobic Fluorinated and Hydrophilic Pegylated Block Copolymer Surfaces: Attachment Strength of the Diatom Navicula and the Green Alga Ulva. Biomacromolecules 2006, 7 (5), 1449-1462.

47. Holland, R.; Dugdale, T. M.; Wetherbee, R.; Brennan, A. B.; Finlay, J. A.; Callow, J. A.; Callow, M. E., Adhesion and Motility of Fouling Diatoms on a Silicone Elastomer. Biofouling 2004, 20 (6), 323-329.

48. Schultz, M. P.; Bendick, J. A.; Holm, E. R.; Hertel, W. M., Economic Impact of Biofouling on a Naval Surface Ship. Biofouling 2010, 27 (1), 87-98.

49. Guo, S.; Puniredd, S. R.; Jańczewski, D.; Lee, S. S. C.; Teo, S. L. M.; He, T.; Zhu, X.; Vancso, G. J., Barnacle Larvae Exploring Surfaces with Variable Hydrophilicity: Influence of Morphology and Adhesion of "Footprint" Proteins by Afm. ACS Appl. Mater. Interfaces 2014, 6 (16), 13667-13676.

50. Aldred, N.; Høeg, J. T.; Maruzzo, D.; Clare, A. S., Analysis of the Behaviours Mediating Barnacle Cyprid Reversible Adhesion. PLoS ONE 2013, 8 (7), e68085.

51. Petrone, L.; Di Fino, A.; Aldred, N.; Sukkaew, P.; Ederth, T.; Clare, A. S.; Liedberg, B., Effects of Surface Charge and Gibbs Surface Energy on the Settlement Behaviour of Barnacle Cyprids (Balanus Amphitrite). Biofouling 2011, 27 (9), 1043-1055.

52. Aldred, N.; Ista, L. K.; Callow, M. E.; Callow, J. A.; Lopez, G. P.; Clare, A. S., Mussel (Mytilus Edulis) Byssus Deposition in Response to Variations in Surface Wettability. Journal of the Royal Society Interface 2006, 3 (6), 37-43.

53. Talley, L. D.; Pickard, G. L.; Emery, W. J.; Swift, J. H., Chapter 3 - Physical Properties of Seawater. In Descriptive Physical Oceanography (Sixth Edition), Academic Press: Boston, 2011; pp 29-65.

54. Talley, L. D.; Pickard, G. L.; Emery, W. J.; Swift, J. H., Chapter 4 - Typical Distributions of Water Characteristics. In Descriptive Physical Oceanography (Sixth Edition), Academic Press: Boston, 2011; pp 67-110. 


\section{Graphical TOC}

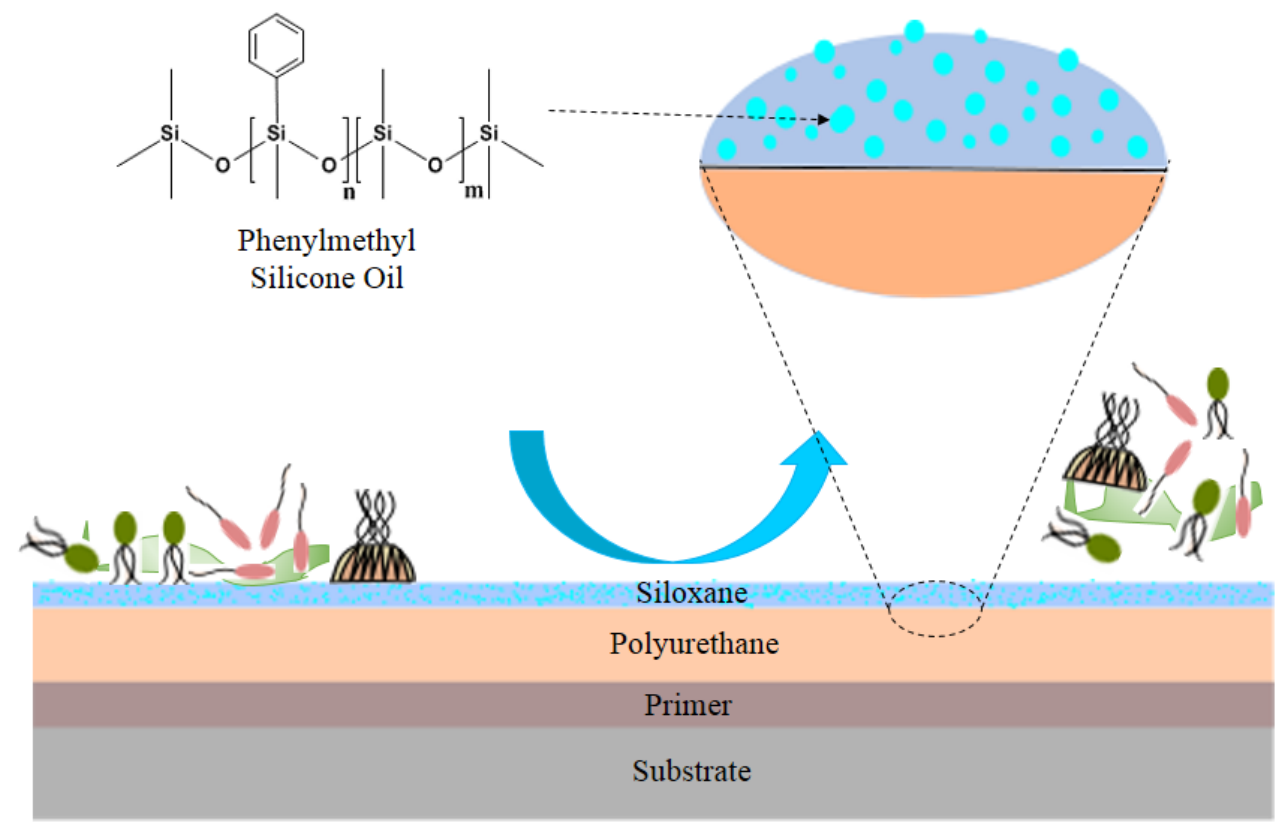

Silicone Oil Modified Siloxane-Polyurethane Fouling Release Coating System 


\section{Supporting Information}

\section{Fouling-release performance of silicone oil-modified siloxane-polyurethane coatings}

Teluka P. Galhenage, ${ }^{\mathrm{a}}$ Dylan Hoffman, ${ }^{\mathrm{a}}$ Samantha D. Silbert, ${ }^{\mathrm{a}}$ Shane J. Stafslien, ${ }^{\mathrm{b}}$ Justin

Daniels, ${ }^{\mathrm{b}}$ Tatjana Miljkovic, ${ }^{\mathrm{c}}$ John A. Finlay, ${ }^{\mathrm{d}}$ Sofia C. Franco, ${ }^{\mathrm{d}}$ Anthony S. Clare, ${ }^{\mathrm{d}}$ Brian T. Nedved, ${ }^{\mathrm{e}}$ Michael G. Hadfield, ${ }^{\mathrm{e}}$ Dean E. Wendt, ${ }^{\mathrm{f}}$ Grant Waltz, ${ }^{\mathrm{f}}$ Lenora Brewer, ${ }^{\mathrm{f}}$ Serena L.M. Teo, ${ }^{\mathrm{g}}$ Lim Chin-Sing,, Dean C. Webster ${ }^{\mathrm{a}^{*}}$

${ }^{a}$ Department of Coatings and Polymeric Materials, North Dakota State University, Fargo ND 58108, USA

${ }^{\mathrm{b}}$ Center for Nanoscale Science and Engineering, North Dakota State University, Fargo, ND 58108, USA

${ }^{\text {c }}$ Department of Statistics, Miami University, Oxford, OH 45056, USA

${ }^{\mathrm{d}}$ School of Marine Science and Technology, Newcastle University, Newcastle upon Tyne, NE1 7RU, UK

${ }^{\text {e }}$ Kewalo Marine Laboratory, University of Hawaii at Manoa, Honolulu HI 96813, USA

${ }^{\mathrm{f}}$ Center for Coastal Marine Sciences, Biological Sciences Department, California Polytechnic State University, San Luis Obispo CA 93407, USA

g Tropical Marine Science Institute, National University of Singapore, Singapore 119227

*Corresponding Author: email: dean.webster@ndsu.edu; Phone: 701-231-8709 


\section{Acrylic Polyol Synthesis}

Butyl acrylate (BA), 2-hydroxyethyl acrylate (HEA), toluene were purchased from Sigma Aldrich. Free radical source VAZO 67 (2',2'-Azobis(2-methylbutyronitrile)) was provided by DuPont. The acrylic polyol was synthesized using free radical polymerization. Briefly, toluene (320 g) was weighed into a 2 liter reaction flask equipped with an overhead mechanical stirrer, thermocouple, $\mathrm{N}_{2}$ purge, and reflux condenser. The temperature of toluene was brought to $90{ }^{\circ} \mathrm{C}$. Then the monomer mixture containing BA (400 g), 2-HEA (100 g), toluene (180 g), and VAZO 67 (20 g) was added drop-wise at a rate of $5.5 \mathrm{~mL} / \mathrm{min}$ while maintaining the temperature of the reaction at $90{ }^{\circ} \mathrm{C}$. Next the temperature was maintained for two hours following the monomer addition. Then $1.33 \mathrm{~g}$ of VAZO 67 dissolved in $12 \mathrm{~g}$ of toluene was added as the chaser. The temperature of the reaction was further maintained for 4 additional hours. Then the resin was transferred in to a container. The resin was characterized for percent solids and molecular weight was evaluated using GPC. The final acrylic polyol was 50\% solids in toluene with number average molecular weight of $9613 \mathrm{~g} / \mathrm{mol}$ with a PDI of 1.74 .

\section{Synthesis of APT-PDMS (20000 g/mol)}

Octamethylcyclotetrasiloxane ( $\left.\mathrm{D}_{4}\right)$, bis(3-aminopropyl)-tetramethyldisiloxane (BAPTMDS) were purchased from Gelest, Inc. Benzyltrimethylammonium hydroxide (in 40\% methanol) was purchased from Sigma Aldrich. The cyclic siloxane monomer $\mathrm{D}_{4}(1200 \mathrm{~g})$ and benzyltrimethyl ammonium hydroxide (3.12 g) catalyst were combined in a one neck round bottom flask. The content was rotary evaporated to remove the methanol. The mixture was then transferred in to a 2 liter reaction flask equipped with a mechanical stirrer, $\mathrm{N}_{2}$ inlet, reflux condenser and a thermo couple. BAPTMDS (15.09 g) was added to the reaction and heated up to $80{ }^{\circ} \mathrm{C}$. Once the

temperature was settled, the reaction was allowed equilibrate overnight. The next day the 
temperature was raised to $170^{\circ} \mathrm{C}$ for an hour to decompose the catalyst. Then the product was transferred to a container. The polymer was characterized for its molecular weight using GPC. Average molecular weight was determined to $19,760 \mathrm{~g} / \mathrm{mol}$ with a PDI of 1.70 .

Table S1: Film thickness measurements of coatings analyzed using XPS

\begin{tabular}{lcc}
\hline \multicolumn{1}{c}{ Coating } & $\begin{array}{c}\text { Average Film } \\
\text { Thickness }(\boldsymbol{\mu m})\end{array}$ & $\begin{array}{c}\text { Standard } \\
\text { Deviation }( \pm)\end{array}$ \\
\hline Siloxane-PU no oil (A4-20) & 45.63 & 0.81 \\
F5-0021-1\% & 46.73 & 1.12 \\
\hline F17-0021-5\% & 47.50 & 0.95 \\
\hline
\end{tabular}

Table S2: ANOVA results for $U$. linza removal at $9 \mathrm{kPa}$

\begin{tabular}{lrrrrr}
\hline \multicolumn{1}{c}{ Source } & DF & $\begin{array}{c}\text { Sum of } \\
\text { Squares }\end{array}$ & $\begin{array}{c}\text { Mean } \\
\text { Square }\end{array}$ & F Value & Pr $>$ F \\
\hline Model & 21 & 21294.92 & 1014.04 & 18.61 & $<.0001$ \\
Error & 110 & 5995.09 & 54.50 & & \\
Corrected Total & 131 & 27290.01 & & & \\
\hline
\end{tabular}

Table S3: $U$. linza removal: Top five performing experimental coatings at $9 \mathrm{kPa}$ statistically compared against control coatings. The table shows t-values for pairwise comparison and the corresponding p-value. *Significant Difference at $\alpha=0.05$.

\begin{tabular}{cccccc}
\hline Exp Coating $\rightarrow$ & Coating 3 & Coating 1 & Coating 10 & Coating 9 & Coating 4 \\
Controls $\downarrow$ & $\mathbf{5 0 2 1}(\mathbf{1 \% )}$ & $\mathbf{1 0 2 5}(\mathbf{1 \% )}$ & $\mathbf{6 0 2 5}(\mathbf{2 \% )}$ & $\mathbf{5 0 2 1}(\mathbf{2 \% )}$ & $\mathbf{6 0 2 5}(\mathbf{1 \% )}$ \\
\hline Coating 19 & $-8.32185^{*}$ & $-7.95942^{*}$ & $-7.9465^{*}$ & $-7.8051^{*}$ & $-7.61259^{*}$ \\
A4-20 & $<.0001$ & $<.0001$ & $<.0001$ & $<.0001$ & $<.0001$ \\
& $-9.35732^{*}$ & $-8.99489^{*}$ & $-8.98197^{*}$ & $-8.84057^{*}$ & $-8.64806^{*}$ \\
T2 & $<.0001$ & $<.0001$ & $<.0001$ & $<.0001$ & $<.0001$ \\
& $-9.98242^{*}$ & $-9.61999^{*}$ & $-9.60706^{*}$ & $-9.46567^{*}$ & $-9.27316^{*}$ \\
PU & $<.0001$ & $<.0001$ & $<.0001$ & $<.0001$ & $<.0001$ \\
& $-7.73196^{*}$ & $-7.36953^{*}$ & $-7.3566^{*}$ & $-7.21521^{*}$ & $-7.0227^{*}$ \\
IS900 & $<.0001$ & $<.0001$ & $<.0001$ & $<.0001$ & $<.0001$ \\
\hline
\end{tabular}


Table S4: $U$. linza removal: Tukey’s comparison for Least squares means of $U$. linza removal for coatings at $9 \mathrm{kPa}$. Least square means with the same letter indicates non-significance.

\section{Tukey's grouping Ulva Removal Coating \# 9kPa LS mean}

\begin{tabular}{|c|c|c|c|c|c|c|c|}
\hline A & & & & & & 53.2515 & 3 \\
\hline A & & & & & & 51.7068 & 1 \\
\hline A & & & & & & 51.6517 & 10 \\
\hline A & & & & & & 51.049 & 9 \\
\hline A & B & & & & & 50.2285 & 4 \\
\hline A & B & & & & & 50.1641 & 13 \\
\hline A & B & & & & & 49.4959 & 6 \\
\hline A & B & & & & & 44.979 & 16 \\
\hline A & B & & & & & 43.6018 & 12 \\
\hline A & B & & & & & 43.1757 & 15 \\
\hline A & B & $\mathrm{C}$ & & & & 42.2589 & 18 \\
\hline A & B & $\mathrm{C}$ & & & & 42.1427 & 5 \\
\hline A & B & C & & & & 41.4689 & 2 \\
\hline A & B & C & & & & 40.7319 & 7 \\
\hline A & B & $\mathrm{C}$ & & & & 39.5418 & 14 \\
\hline \multirow[t]{6}{*}{ A } & B & C & & & & 38.1946 & 8 \\
\hline & B & C & $\mathrm{D}$ & & & 35.0582 & 11 \\
\hline & & C & $\mathrm{D}$ & E & & 27.1557 & 17 \\
\hline & & & $\mathrm{D}$ & $\mathrm{E}$ & $\mathrm{F}$ & 20.2958 & IS900 \\
\hline & & & & $\mathrm{E}$ & F & 17.7816 & 19 (A4-20) \\
\hline & & & & $\mathrm{E}$ & F & 13.3681 & $\mathrm{~T} 2$ \\
\hline & & & & & $\mathrm{F}$ & 10.7038 & PU \\
\hline
\end{tabular}


Table S5: ANOVA results for $U$. linza removal at $67 \mathrm{kPa}$

\begin{tabular}{lrrrrr}
\hline Source & DF & $\begin{array}{c}\text { Sum of } \\
\text { Squares }\end{array}$ & $\begin{array}{c}\text { Mean } \\
\text { Square }\end{array}$ & F Value & Pr $>$ F \\
\hline Model & 21 & 34569.30 & 1646.16 & 30.09 & $<.0001$ \\
Error & 110 & 6017.37 & 54.70 & & \\
Corrected Total & 131 & 40586.67 & & & \\
\hline
\end{tabular}

Table S6: $U$. linza removal: Top three performing experimental coatings at $67 \mathrm{kPa}$ statistically compared against control coatings. The table shows t-values for each comparison and the corresponding p-value. *Significant Difference at $\alpha=0.05$.

\begin{tabular}{|c|c|c|c|c|c|}
\hline $\begin{array}{c}\text { Exp Coating } \rightarrow \\
\text { Controls } \downarrow\end{array}$ & $\begin{array}{l}\text { Coating } 10 \\
6025(2 \%)\end{array}$ & $\begin{array}{l}\text { Coating } 3 \\
5021(1 \%)\end{array}$ & $\begin{array}{l}\text { Coating } 1 \\
1025(1 \%)\end{array}$ & $\begin{array}{l}\text { Coating } 9 \\
5021(2 \%)\end{array}$ & $\begin{array}{r}\text { Coating } 4 \\
6025(1 \%)\end{array}$ \\
\hline Coating 19 & $-4.33452 *$ & $-3.71018 *$ & -3.65439 & -3.57717 & -2.91376 \\
\hline A4-20 & 0.0058 & 0.0463 & 0.0546 & 0.0683 & 0.3346 \\
\hline $\mathbf{T} 2$ & $\begin{array}{c}-9.33078 * \\
<.0001\end{array}$ & $\begin{array}{l}-8.70644^{*} \\
<.0001\end{array}$ & $\begin{array}{l}-8.65065^{*} \\
<.0001\end{array}$ & $\begin{array}{c}-8.57342 * \\
<.0001\end{array}$ & $\begin{array}{c}-7.91002 * \\
<.0001\end{array}$ \\
\hline PU & $\begin{array}{c}-16.5807^{*} \\
<.0001\end{array}$ & $\begin{array}{l}-15.9564^{*} \\
<.0001\end{array}$ & $\begin{array}{c}-15.9006^{*} \\
<.0001\end{array}$ & $\begin{array}{c}-15.8233^{*} \\
<.0001\end{array}$ & $\begin{array}{c}-15.1599 * \\
<.0001\end{array}$ \\
\hline IS900 & $\begin{array}{c}-10.4598 * \\
<.0001\end{array}$ & $\begin{array}{c}-9.83546^{*} \\
<.0001\end{array}$ & $\begin{array}{l}-9.77967^{*} \\
<.0001\end{array}$ & $\begin{array}{l}-9.70245^{*} \\
<.0001\end{array}$ & $\begin{array}{c}-9.03904^{*} \\
<.0001\end{array}$ \\
\hline
\end{tabular}


Table S7: $U$. linza removal: Tukey's comparison for Least squares means of $U$. linza removal for coatings at $67 \mathrm{kPa}$. Least square means with the same letter indicates non-significance.

\begin{tabular}{|c|c|c|c|c|}
\hline \multicolumn{3}{|c|}{ Tukey's grouping } & \multirow{2}{*}{$\begin{array}{c}\text { Ulva Removal } \\
\begin{array}{c}\text { 67kPa LS } \\
\text { mean }\end{array} \\
82.39338\end{array}$} & \multirow{2}{*}{$\begin{array}{c}\text { Coating \# } \\
\\
10\end{array}$} \\
\hline A & & & & \\
\hline A & B & & 79.72733 & 3 \\
\hline A & B & C & 79.4891 & 1 \\
\hline A & B & $\mathrm{C}$ & 79.15933 & 9 \\
\hline A & B & $\mathrm{C}$ & 76.32648 & 4 \\
\hline A & B & C & 75.2338 & 5 \\
\hline A & B & $\mathrm{C}$ & 75.11485 & 6 \\
\hline A & B & $\mathrm{C}$ & 75.01478 & 15 \\
\hline A & B & C & 73.666 & 7 \\
\hline A & B & $\mathrm{C}$ & 73.4351 & 2 \\
\hline A & B & C & 72.74301 & 13 \\
\hline A & B & $\mathrm{C}$ & 72.67015 & 17 \\
\hline A & B & $\mathrm{C}$ & 72.63992 & 14 \\
\hline A & B & $\mathrm{C}$ & 72.42177 & 12 \\
\hline A & B & $\mathrm{C}$ & 72.20804 & 16 \\
\hline A & B & $\mathrm{C}$ & 68.67201 & 8 \\
\hline \multirow[t]{6}{*}{ A } & B & C & 67.63361 & 11 \\
\hline & B & $\mathrm{C}$ & 64.41499 & 18 \\
\hline & & $\mathrm{C}$ & 63.88418 & 19 (A4-20) \\
\hline & & $\mathrm{D}$ & 42.54926 & $\mathrm{~T} 2$ \\
\hline & & $\mathrm{D}$ & 37.72811 & IS900 \\
\hline & & & 11.59077 & PU \\
\hline
\end{tabular}


Table S8: ANOVA results for $N$. incerta (diatom) removal at 20 psi.

\begin{tabular}{lcrrrr}
\hline \multicolumn{1}{c}{ Source } & DF & $\begin{array}{c}\text { Sum of } \\
\text { Squares }\end{array}$ & $\begin{array}{c}\text { Mean } \\
\text { Square }\end{array}$ & F Value & Pr $>$ F \\
\hline Model & 22 & 14629.22 & 664.96 & 22.18 & $<.0001$ \\
Error & 46 & 1379.14 & 29.98 & & \\
Corrected Total & 68 & 16008.35 & & & \\
\hline
\end{tabular}

Table S9: $N$. incerta (diatom) removal: Top five performing experimental coatings at 20 psi statistically compared against control coatings. The table shows t-values for each comparison and the corresponding p-value. *Significant Difference at $\alpha=0.05$, No symbol means the two coatings are similar in performance.

\begin{tabular}{|c|c|c|c|c|c|}
\hline $\begin{array}{c}\text { Exp Coating } \rightarrow \\
\quad \text { Controls } \downarrow\end{array}$ & $\begin{array}{l}\text { Coating } 16 \\
6025(5 \%)\end{array}$ & $\begin{array}{l}\text { Coating } 13 \\
1025(5 \%)\end{array}$ & $\begin{array}{c}\text { Coating } 7 \\
1025(2 \%)\end{array}$ & $\begin{array}{c}\text { Coating } 1 \\
1025(1 \%)\end{array}$ & $\begin{array}{r}\text { Coating } 5 \\
0021(1 \%)\end{array}$ \\
\hline $\begin{array}{l}\text { Coating } 19 \\
\text { A4-20 }\end{array}$ & $\begin{array}{c}2.769187 \\
0.4652\end{array}$ & $\begin{array}{c}3.423688 \\
0.137\end{array}$ & $\begin{array}{c}3.747879 \\
0.0631\end{array}$ & $\begin{array}{c}3.77471 \\
0.059\end{array}$ & $\begin{array}{c}3.959984 * \\
0.0363\end{array}$ \\
\hline T2 & $\begin{array}{c}1.224217 \\
0.9998\end{array}$ & $\begin{array}{c}1.878719 \\
0.9545\end{array}$ & $\begin{array}{c}2.202909 \\
0.8347\end{array}$ & $\begin{array}{c}2.22974 \\
0.8206\end{array}$ & $\begin{array}{c}2.415015 \\
0.709\end{array}$ \\
\hline PU & $\begin{array}{c}9.255145^{*} \\
<.0001\end{array}$ & $\begin{array}{c}9.909647 * \\
<.0001\end{array}$ & $\begin{array}{c}10.23384^{*} \\
<.0001\end{array}$ & $\begin{array}{c}10.26067 * \\
<.0001\end{array}$ & $\begin{array}{c}10.44594^{*} \\
<.0001\end{array}$ \\
\hline IS700 & $\begin{array}{c}3.173087 \\
0.2324\end{array}$ & $\begin{array}{c}3.827589 \\
0.0515\end{array}$ & $\begin{array}{c}4.151779 * \\
0.0215\end{array}$ & $\begin{array}{c}4.17861^{*} \\
0.0199\end{array}$ & $\begin{array}{c}4.363885^{*} \\
0.0117\end{array}$ \\
\hline IS900 & $\begin{array}{c}5.928335^{*} \\
<.0001\end{array}$ & $\begin{array}{c}6.582837^{*} \\
<.0001\end{array}$ & $\begin{array}{c}6.907027^{*} \\
<.0001\end{array}$ & $\begin{array}{c}6.933858^{*} \\
<.0001\end{array}$ & 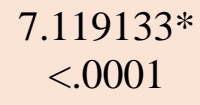 \\
\hline
\end{tabular}


Table S10: Tukey's comparison for Least squares means of diatom removal for coatings at 20 psi. Least square means with the same letter indicates non-significance.

\section{Tukey's grouping}

\section{Diatom Coating \# \\ Removal 20psi \\ LS mean}

\begin{tabular}{|c|c|c|c|c|c|c|c|c|c|}
\hline A & & & & & & & & 94.7754 & PU \\
\hline A & B & & & & & & & 79.9021 & IS900 \\
\hline & B & C & & & & & & 67.5841 & IS700 \\
\hline & B & C & D & & & & & 65.7784 & 19 \\
\hline & & C & D & $\mathrm{E}$ & & & & 58.8713 & $\mathrm{~T} 2$ \\
\hline & & C & D & $\mathrm{E}$ & $\mathrm{F}$ & & & 53.3981 & 16 \\
\hline & & C & D & E & $\mathrm{F}$ & G & & 50.472 & 13 \\
\hline & & & D & E & $\mathrm{F}$ & G & & 49.0226 & 7 \\
\hline & & & D & E & $\mathrm{F}$ & G & & 48.9027 & 1 \\
\hline & & & & $\mathrm{E}$ & $\mathrm{F}$ & G & $\mathrm{H}$ & 48.0744 & 5 \\
\hline & & & & $\mathrm{E}$ & $\mathrm{F}$ & G & $\mathrm{H}$ & 47.5733 & 8 \\
\hline & & & & E & $\mathrm{F}$ & G & $\mathrm{H}$ & 46.9634 & 6 \\
\hline & & & & $\mathrm{E}$ & $\mathrm{F}$ & G & $\mathrm{H}$ & 46.5285 & 17 \\
\hline & & & & $\mathrm{E}$ & $\mathrm{F}$ & G & $\mathrm{H}$ & 46.263 & 18 \\
\hline & & & & E & F & G & $\mathrm{H}$ & 44.3305 & 11 \\
\hline & & & & $\mathrm{E}$ & $\mathrm{F}$ & G & $\mathrm{H}$ & 43.2351 & 4 \\
\hline & & & & $\mathrm{E}$ & $\mathrm{F}$ & G & $\mathrm{H}$ & 41.7553 & 12 \\
\hline & & & & & $\mathrm{F}$ & G & $\mathrm{H}$ & 41.2634 & 14 \\
\hline & & & & & $\mathrm{F}$ & G & $\mathrm{H}$ & 40.7551 & 2 \\
\hline & & & & & $\mathrm{F}$ & G & $\mathrm{H}$ & 37.2877 & 15 \\
\hline & & & & & & G & $\mathrm{H}$ & 36.0557 & 3 \\
\hline & & & & & & G & $\mathrm{H}$ & 33.9785 & 9 \\
\hline & & & & & & & $\mathrm{H}$ & 30.9737 & 10 \\
\hline
\end{tabular}


Table S11: ANOVA results for C. lytica (bacteria) removal at 10 psi.

\begin{tabular}{|lccccc}
\hline \multicolumn{1}{c}{ Source } & DF & $\begin{array}{c}\text { Sum of } \\
\text { Squares }\end{array}$ & Mean Square & F Value & Pr $>$ F \\
\hline Model & 17 & 1625.2287 & 95.60169 & 3.09 & 0.0022 \\
\hline Error & 36 & 1115.2995 & 30.980541 & & \\
\hline Corrected Total & 53 & 2740.5282 & & & \\
\hline
\end{tabular}

Table S12: C. lytica (bacteria) removal: Top five performing experimental coatings at 10 psi statistically compared against control coatings. The table shows t-values for each comparison and the corresponding p-value in the parentheses. *Significant Difference at $\alpha=0.05$, No symbol means the two coatings are similar in performance.

\begin{tabular}{cccccc}
\hline $\begin{array}{c}\text { Exp Coating } \rightarrow \\
\text { Controls } \downarrow\end{array}$ & $\begin{array}{c}\text { Coating 1 } \\
\mathbf{1 0 2 5}(\mathbf{1 \% )}\end{array}$ & $\begin{array}{c}\text { Coating 5 } \\
\mathbf{0 0 2 1}(\mathbf{1 \% )})\end{array}$ & $\begin{array}{c}\text { Coating 16 } \\
\mathbf{6 0 2 5}(\mathbf{5 \% )}\end{array}$ & $\begin{array}{c}\text { Coating 8 } \\
\mathbf{1 0 4 3}(\mathbf{2 \% )}\end{array}$ & $\begin{array}{c}\text { Coating 17 } \\
\mathbf{0 0 2 1}(\mathbf{5 \% )}\end{array}$ \\
\hline Coating 19 & -1.39419 & 0.572544 & 0.660138 & 1.001329 & 1.408036 \\
A4-20 & 0.9985 & 1 & 1 & 1 & 0.9983 \\
T2 & -2.38345 & -0.41672 & -0.32912 & 0.012066 & 0.418773 \\
& 0.7295 & 1 & 1 & 1 & 1 \\
PU & -0.29663 & 1.670102 & 1.757696 & 2.098886 & 2.505594 \\
& 1 & 0.9863 & 0.9764 & 0.8835 & 0.648 \\
IS700 & $-5.27972 *$ & -3.31299 & -3.2254 & -2.88421 & -2.4775 \\
& 0.0007 & 0.1744 & 0.2093 & 0.3902 & 0.6672 \\
IS900 & $5.358331^{*}$ & $7.32506^{*}$ & $7.412654^{*}$ & $7.753844 *$ & $8.160551^{*}$ \\
& 0.0005 & $<.0001$ & $<.0001$ & $<.0001$ & $<.0001$ \\
\hline
\end{tabular}


Table S13: Tukey’s comparison for Least squares means of $C$. lytica (bacteria) removal for coatings at 10 psi. Least square means with the same letter indicates non-significance.

\section{Tukey's grouping Bacteria Removal Coating \# 10psi LS mean}

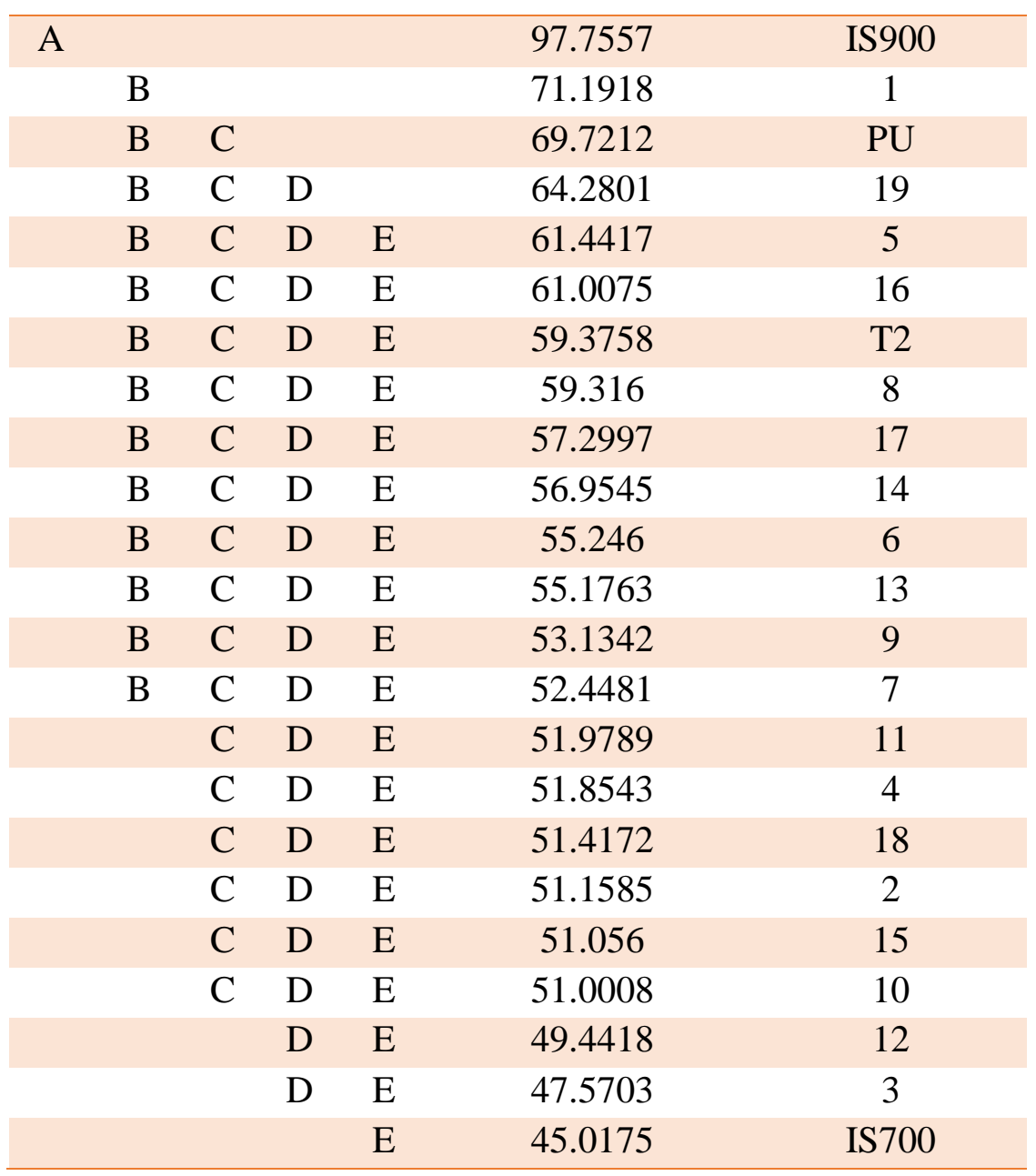


Table S14: ANOVA results for barnacle (A. amphitrite) adhesion.

\begin{tabular}{|lcccccc}
\hline \multicolumn{1}{c}{ Source } & DF & $\begin{array}{c}\text { Sum of } \\
\text { Squares }\end{array}$ & Mean Square & F Value & Pr $>$ F \\
\hline Model & 21 & 15220.26 & 724.77 & 4.05 & $<.0001$ \\
\hline Error & 88 & 15767.52 & 179.18 & & \\
\hline Corrected Total & 109 & 30987.79 & & & & \\
\hline
\end{tabular}

Table S15: barnacle (A. amphitrite) adhesion: Top three performing experimental coatings statistically compared against control coatings. The table shows t-values for each comparison and the corresponding p-value. *Significant Difference at $\alpha=0.05$, No symbol means the two coatings are similar in performance.

\begin{tabular}{cccccc|}
\hline $\begin{array}{c}\text { Exp Coating } \rightarrow \\
\text { Controls } \downarrow\end{array}$ & $\begin{array}{c}\text { Coating 6 } \\
\mathbf{0 0 2 5}(\mathbf{1 \% )}\end{array}$ & $\begin{array}{c}\text { Coating 15 } \\
\mathbf{5 0 2 1}(\mathbf{5 \% )}\end{array}$ & $\begin{array}{c}\text { Coating 5 } \\
\mathbf{0 0 2 1}(\mathbf{1 \% )}\end{array}$ & $\begin{array}{c}\text { Coating 10 } \\
\mathbf{6 0 2 5}(\mathbf{2 \% )}\end{array}$ & $\begin{array}{c}\text { Coating 1 } \\
\mathbf{1 0 2 5}(\mathbf{1 \% )}\end{array}$ \\
\hline Coating 19 & -3.09042 & -2.98098 & -2.95907 & -2.83132 & -2.40886 \\
A4-20 & 0.2383 & 0.2979 & 0.3108 & 0.3923 & 0.6976 \\
T2 & $-4.12634 *$ & $-4.0169 *$ & $-3.99499^{*}$ & $-3.86724 *$ & -3.44478 \\
& 0.0136 & 0.0194 & 0.0208 & 0.031 & 0.103 \\
\hline IS700 & -2.06707 & -1.95763 & -1.93572 & -1.80797 & -1.38551 \\
& 0.893 & 0.9324 & 0.9389 & 0.9683 & 0.9987 \\
\hline IS900 & -0.84953 & -0.74009 & -0.71818 & -0.59043 & -0.16797 \\
& 1 & 1 & 1 & 1 & 1 \\
\hline
\end{tabular}


Table S16: Tukey's comparison for Least squares means of barnacle (A. amphitrite) adhesion for coatings. Least square means with the same letter indicates non-significance.

\section{Tukey's Release Score Coating \# grouping LS mean}

\begin{tabular}{ccccc}
\hline A & & & 99.0465 & 6 \\
A & & & 98.12 & 15 \\
A & & & 97.9345 & 5 \\
A & & & 96.853 & 10 \\
A & B & & 93.2765 & 1 \\
A & B & C & 91.8545 & IS900 \\
A & B & C & 90.797 & 9 \\
A & B & C & 90.7285 & 16 \\
A & B & C & 88.111 & 11 \\
A & B & C & 83.8675 & 7 \\
A & B & C & 83.219 & 4 \\
A & B & C & 81.547 & IS700 \\
A & B & C & 80.5785 & 13 \\
A & B & C & 79.175 & 3 \\
A & B & C & 78.151 & 12 \\
A & B & C & 72.8835 & 19 \\
A & B & C & 70.2235 & 2 \\
A & B & C & 70.0345 & 17 \\
A & B & C & 69.976 & 18 \\
& B & C & 64.7345 & 14 \\
\hline & B & C & 64.1135 & T2 \\
\hline
\end{tabular}

